\title{
Effect of Bacterial Endotoxin and Interleukin-1 $\beta$ on Hippocampal Serotonergic Neurotransmission, Behavioral Activity, and Free Corticosterone Levels: An in vivo Microdialysis Study
}

\author{
Astrid C. E. Linthorst, Cornelia Flachskamm, Peter Müller-Preuss, Florian Holsboer, and \\ Johannes M. H. M. Reul \\ Max Planck Institute of Psychiatry, Clinical Institute, Department of Neuroendocrinology, 80804 Munich, Germany
}

In this study the effect of immune system stimulation and intracerebroventricular (i.c.v.) administration of interleukin$1 \beta$ (IL-1 $\beta$ ) on hippocampal serotonergic neurotransmission, behavioral activlty, and the hypothalamic-pituitaryadrenocortical (HPA) axis is described. An in vivo microdialysis method was used to measure hippocampal extracellular concentrations of serotonin (5-HT) and its metabolite 5-hydroxyindoleacetic acid (5-HIAA) in conscious, freely moving rats. In addition, we established a method to continuously monitor free corticosterone levels in dialysates. Behavioral activity was scored by measuring the time during which rats were active (locomotion, grooming, eating, drinking). We found a significant, positive relationship between behavioral activity and hippocampal extracellular concentrations of 5-HT. Intraperitoneal (i.p.) administration of the bacterial endotoxin lipopolysaccharide (LPS; 30,100 , and $300 \mu \mathrm{g} / \mathrm{kg}$ body weight) produced an increase in the extracellular concentrations of 5-HT and 5-HIAA in the hippocampus, which was paralleled by a significant decline in behavioral activity and a marked increase in extracellular corticosterone levels. Thus, the close correlation between hippocampal extracellular 5-HT levels and behavioral activity observed in control rats was disrupted in the LPS-treated animals. The effects of i.p. LPS could be mimicked by i.c.v. application of recombinant

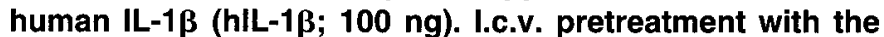
IL-1 receptor antagonist (IL-1ra; $10 \mu \mathrm{g}$ ) antagonized the hIL-1 $\beta$-induced effects. IL-1ra showed no intrinsic effects. Furthermore, it was found that i.c.v. pretreatment with IL1 ra $(10 \mu \mathrm{g})$ significantly attenuated the i.p. LPS-induced (100 $\mu \mathrm{g} / \mathrm{kg}$ body weight) rise in hippocampal extracellular 5-HT levels. No significant effect of IL-1 ra was found on LPS-induced changes in extracellular levels of 5-HIAA and corticosterone, and behavioral activity.

\footnotetext{
Received Sept. 6, 1994; revised Oct. 21, 1994; accepted Oct. 26, 1994.

We thank Dr. E. B. De Souza and The DuPont Merck Pharmaceutical Company, Wilmington, $\mathrm{DE}$, for the generous gift of human recombinant interleukin$1 \beta$ and interleukin- 1 receptor antagonist, and Dr. C. Van Valkenburg for expert advice on the HPLC-electrochemical detection method. We thank Dr. A. Yassouridis for his expert advice on the statistical analyses. Dr. R. Landgraf is gratefully acknowledged for reviewing the manuscript. Ms. M. Söder is acknowledged for technical assistance and Ms. E. Fesl is thanked for secretarial support. This study was subsidized by the Volkswagen Stiftung (I/68 430 and I/66 949).

Correspondence should be addressed to A. C. E. Linthorst, Ph.D., Max Planck Institute of Psychiatry, Clinical Institute. Department of Neuroendocrinology, Kraepelinstrasse 2, 80804 Munich, Germany.

Copyright (C) 1995 Society for Neuroscience $0270-6474 / 95 / 152920-15 \$ 05.00 / 0$
}

Taken together, these results suggest that the hippocampus, and more specifically the raphe-hippocampal serotonergic system, participates in the CNS responses to an immune stimulus. Moreover, the present study supports the notion that centrally acting IL-1 substantially contributes to the hippocampal serotonergic neurotransmission changes observed following a peripheral immune challenge.

[Key words: in vivo microdialysis, bacterial endotoxin, interleukin-1 $\beta$, interleukin-1 receptor antagonist, serotonin, corticosterone, hippocampus, rat, behavior]

During the past years evidence has accumulated for a bidirectional communication between the CNS and the immune system. Hence, the brain modulates immune processes using neurotransmitters and endocrine hormones as principal communicators (Felten and Felten, 1991), and, conversely, cytokines [e.g., interleukin-1 (IL-1), IL-2, IL-6, and tumor necrosis factor (TNF)] secreted by distinct cell populations of the immune system produce multiple effects on the level of the CNS, manifesting as marked changes in neuroendocrine, autonomic, and behavioral processes (extensively reviewed by Besedovsky and Del Rey, 1992). Stimulation of cytokine production due to administration of the inflammatory agent lipopolysaccharide (LPS; i.e., gramnegative bacterial endotoxin) or inoculation of $\mathrm{IL}-1$ increases hypothalamic-pituitary-adrenocortical (HPA) axis activity as indicated by increases in circulating plasma adrenocorticotropin (ACTH) and corticosterone levels (for review see Bateman et al., 1989; Dunn, 1990; Besedovsky and Del Rey, 1992). Moreover, injection of LPS or IL-1 in rodents causes striking changes reminiscent of sickness, such as piloerection, curled body posture, and decreased food intake, which in part may be associated with the development of fever (Hart, 1988; Rothwell, 1991; Kent et al., 1992).

On the level of the brain, however, the neural circuitry involved in the processing of humoral and/or nervous signals from the immune system largely remains to be characterized. Until now, most studies have focused on the hypothalamus mainly to identify cytokine- and/or LPS-responsive neural circuits involved in neuroendocrine and autonomic regulation. The most consistent effect in these studies, irrespective of the investigated substance (LPS or IL-1), the route of administration [intraperitoneal (i.p.), intracerebroventricular (i.c.v.), or intracerebral (i.c.)], or experimental procedure (postmortem tissue levels or in vivo release), was an increase in noradrenergic turnover in this brain structure (Kabiersch et al., 1988; Dunn, 1988, 1992a,b; Mefford et al., 1990; Mohankumar and Quadri, 1993; Shintani 
et al., 1993; A. C. E. Linthorst and J. M. H. M. Reul, unpublished observations). However, it has been suggested that the neuroendocrine, autonomic (f.i. fever), and behavioral changes after an immune challenge may be regarded as adaptive responses to regain homenstasis (Rothwell, 1991; Besedovsky and Del Rey, 1992; Kent et al., 1992). It is well known from studies on stress that higher limbic brain centers like the hippocampus often participate in such homeostatic responses (de Kloet, 1991). Thus, since immune stimulation may be regarded as a stressful event (Kushner, 1982), the hippocampus may be involved in the regulation of CNS-mediated (patho)physiological responses following an immune challenge. At this moment, however, the effects of an immune challenge or cytokine administration on hippocampal neurotransmission is largely unknown. The serotonergic projection originating from the midbrain raphe nuclei represents one of the major afferent neurotransmitter systems of the hippocampus (Swanson et al., 1987; Jacobs and Azmitia, 1992). Therefore, we started a series of experiments on the effects of i.p. LPS treatment and i.c.v. administration of recombinant human IL-1 $\beta$ (hIL-1 $\beta$ ) on hippocampal serotonergic neurotransmission using in vivo microdialysis in freely moving rats. Since, as noted above, the hippocampus plays an important role in the regulation of adaptive behavior and HPA axis activity, behavioral activity and free corticosterone levels were monitored in parallel.

\section{Materials and Methods}

\section{Animals}

Male Wistar rats were purchased from Charles River Wiga, Sulzfeld, Germany. Rats were housed six per cage under standard lighting (lights on from $730-1930 \mathrm{hr})$ and temperature $\left(22^{\circ} \mathrm{C}\right)$ conditions, and had free access to food and water. At the time of surgery, the body weight was about $250 \mathrm{gm}$. Handling of the animals (once a day, $5 \mathrm{~min}$ per rat) was started 1 week before surgery and continued until the start of the experiment (total handling period 13-16 d).

\section{Surgical procedures}

One week after arrival of the rats, a guide cannula (CMA/12, CMA Microdialysis AB, Stockholm, Sweden), just entering the hippocampus at the dorsal site, was implanted under halothane anesthesia using a stereotactic apparatus. Coordinates, according to the atlas of Paxinos and Watson (1982) with the toothbar set at $-3.3 \mathrm{~mm}$, were lateral 5.2 $\mathrm{mm}$, posterior $5.1 \mathrm{~mm}$, and ventral $4.0 \mathrm{~mm}$ with bregma as an overall zero. The guide cannula was fixed to the skull with three stainless steel screws and dental cement and the wound was closed with surgical silk. For the experiments described under protocol $C$ and $D$, a polyethylene guide cannula was additionally implanted in the lateral cerebral ventricle, according to the method of Brakkee et al. (1979), ipsilateral to the guide cannula for hippocampal microdialysis. $\Lambda$ nimals were equipped with a plastic collar around the neck to connect a liquid swivel during the experiment. After surgery, rats were housed individually in special plexiglass cages $(1 \times \mathrm{w} \times \mathrm{h}=25 \times 25 \times 35 \mathrm{~cm})$ such that they could see, hear, and smell each other, and with food and water ad libitum.

Six or nine days after implantation of the guide cannula, rats were moved to the experimental room (with similar environmental conditions as in the animal room facilities) and a microdialysis probe with a length of $4 \mathrm{~mm}$ (CMA/12, CMA/Microdialysis AB, Stockholm, Sweden; molecular cutoff $20,000 \mathrm{Da}$ ) was inserted slowly into the hippocampus. The insertion was done under light halothane anesthesia (anesthesia lasted about $3 \mathrm{~min}$ ) to prevent movement of the rat's head during implantation. Animals were connected to a liquid swivel attached to a counterbalancing arm (CMA/Microdialysis AB, Stockholm, Sweden) and the microdialysis probe was perfused continuously with sterile, pyrogen-free Ringer solution (Delta Pharma, Pfullingen, Germany; 147 $\mathrm{mM} \mathrm{NaCl}, 4 \mathrm{mM} \mathrm{KCl}, 2.25 \mathrm{~mm} \mathrm{CaCl}$ ) at a flow rate of $2 \mu \mathrm{l} / \mathrm{min}$ using a microinfusion pump (CMA/Microdialysis AB, Stockholm, Sweden). FEP tubing with a dead volume of $1.2 \mu \mathrm{l} / 100 \mathrm{~mm}$ length (CMA/Microdialysis AB, Stockholm, Sweden) was used for all connections.

\section{Experimental protocols}

General procedures. Experiments were started at $900 \mathrm{hr}$ on day 2, that is, $40-45 \mathrm{hr}$ after insertion of the microdialysis probe, a time point at which the levels of serotonin [5-hydroxytryptamine (5-HT)] reflect neuronal release for $90-95 \%$ (as revealed by previous experiments with the $\mathrm{Na}^{+}$channel blocker tetrodotoxin). Microdialysis samples were collected in a vial on top of the swivel. Since behavioral activity was an important paradigm in our experimental design, great care was taken to avoid unexpected noise in the experimental room to disturb the animals as little as possible.

In one series of experiments [i.p. administration of I.PS (dose-response experiment, protocol A)], collection vials were exchanged every $15 \mathrm{~min}$ (total sample volume $30 \mu \mathrm{l}$ ). After addition of $20 \mu \mathrm{l} 0.025 \mathrm{M}$ acctic acid the collected sample of each vial was used for measurement of 5-HT and its metabolite 5-hydroxyindoleacetic acid (5-HIAA) using high pressure/performance liquid chromatography with electrochemical detection (see below). This measurement occurred eilher direclly after collection or samples were stored at $-80^{\circ} \mathrm{C}$. Storage at $-80^{\circ} \mathrm{C}$ had no detrimental effects on 5-HT and 5-HIAA. In other sets of experiments [protocol B, i.p. administration of $100 \mu \mathrm{g} / \mathrm{kg}$ body weight LPS; protocol C, i.c.v. administration of IL-1 receptor antagonist (IL-1ra) and hIL-1 $\beta$; protocol D, i.c.v. administration of IL-1ra and i.p. administration of LPS]) collection vials were exchanged every $30 \mathrm{~min}$ (total sample volume $60 \mu \mathrm{l}$ ) and the collected sample of each vial was divided into two parts for measurement of 5-HT, 5-HIAA, and corticosterone. An aliquot of $25 \mu \mathrm{l}$ was taken and mixed with $20 \mu \mathrm{l} 0.025 \mathrm{M}$ acetic acid. This mixture was used for measurement of 5-HT and 5-HIAA. The remaining part of the collected sample was stored at $-20^{\circ} \mathrm{C}$ for measurement of corticosterone by radioimmunoassay (RIA, see below).

During the sampling period, the behavioral activity of each animal was observed. A detailed descriplion of the behavior (locomotor activity, rearing, grooming, eating, and drinking) was written down in a protocol. In the first series of experiments (sample duration $15 \mathrm{~min}$, protocol A) the behavioral activity was classified in three categories of arbitrary units (1-3), in which a behavioral activity of " 1 " meant that the rat was behaviorally active (locomotion, rearing, grooming, eating, and drinking behavior) during less than $1 \mathrm{~min}$ of a $15 \mathrm{~min}$ period, "2" denotes activity during more than 1 min but less than 7.5 min of a 15 min period, and " 3 " indicates activity during more than $7.5 \mathrm{~min}$ of a 15 min period. In the other series of experiments (sample duration 30 min, protocol B, C, and D) the behavioral activity was also classified in three categories of arbitrary units (1-3), in which a behavioral activity of " 1 " meant that the rat was behaviorally active during less than 2 min of a $30 \mathrm{~min}$ period, " 2 " denotes activity during more than 2 min but less than 15 min of a $30 \mathrm{~min}$ period, and " 3 " indicates activity during more than $15 \mathrm{~min}$ of a $30 \mathrm{~min}$ period. Behavioral scoring was conducted in a "blind" fashion; that is, during scoring the observer was ignorant of any dialysate parameter value and regime of treatment of any animal.

Protocol A. In a first series of experiments, eight 15 min samples were collected between 900 and $1100 \mathrm{hr}$ for measurement of basal (preinjection) levels of 5-HT and 5-HIAA, after which rats were injected i.p. with sterile, pyrogen-free saline $(1.0 \mathrm{ml} / \mathrm{kg}$ body weight $)$ or LPS (Salmonella abortus equi, Sigma). Three doses of LPS dissolved in sterile, pyrogen-free saline were tested: 30,100 , and $300 \mu \mathrm{g} / \mathrm{kg}$ body weight diluted to a volume of $1.0 \mathrm{ml} / \mathrm{kg}$ body weight. After the injection, $15 \mathrm{~min}$ samples were collected for another $6 \mathrm{hr}(1100-1700 \mathrm{hr})$.

Protocol $B$. In a second set of experiments, five $30 \mathrm{~min}$ samples were collected between 900 and $1130 \mathrm{hr}$ for measurement of basal (preinjection) levels of 5-HT, 5-HIAA, and corticosterone, after which rats were injected i.p. with saline or LPS $(100 \mu \mathrm{g} / \mathrm{kg}$ body weight; further details as described under protocol A). After the injection, 30 min samples were collected for another $6 \mathrm{hr}(1130-1730 \mathrm{hr})$.

Protocol $C$. In a third series of experiments, five 30 min samples were collected between $900-1130 \mathrm{hr}$ for measurement of basal concentrations of 5-HT, 5-HIAA, and corticosterone, after which rats received two i.c.v. injections separated by 6 min. The rats were divided into four groups. The first group received two i.c.v. injections of sterile, pyrogenfree saline $(10 \mu 1)$. The second group received first an injection of saline followed by an injection of hIL-1 $\beta$ (100 ng). The third group was first injected with IL-1ra $(10 \mu \mathrm{g})$ followed by an injection of saline $(10 \mu \mathrm{l})$. The fourth group received an injection of IL-1ra $(10 \mu \mathrm{g})$ followed by an injection of hIL-1 $\beta$ (100 ng). After the injections, 30 min samplcs were collected for another $6 \mathrm{hr}(1130-1730 \mathrm{hr})$.

Protocol D. In a fourth series of experiments, five $30 \mathrm{~min}$ samples 
Figure 1. Extracellular concentrations of 5-HT and 5-HIAA in the hippocampus of saline-treated rats during different behavioral activity stages as found in experiments described under protocol A (15 min samples; i.p saline; $A$ and $C$, respectively) and under protocol C (30 min samples; i.c.v. saline/ i.c.v. saline; $B$ and $D$, respectively). Values represent means \pm SEM $(n=$ 5-6). Data on 5-HT and 5-HIAA are expressed as fmol/sample and $\mathrm{pmol} /$ sample, respectively. Please note that the overall levels observed in protocol $\mathrm{C}$ are about twice as high as those found in protocol $\mathrm{A}$, due to the difference in sampling time ( 30 vs $15 \mathrm{~min}$ ). $*$, significantly different from behavioral activity score " $1 " ;+$, significantly different from activity score " 2 " (paired $t$ test; for further details on the statistical analysis see Calculations and statistical procedures in Materials and Methods).
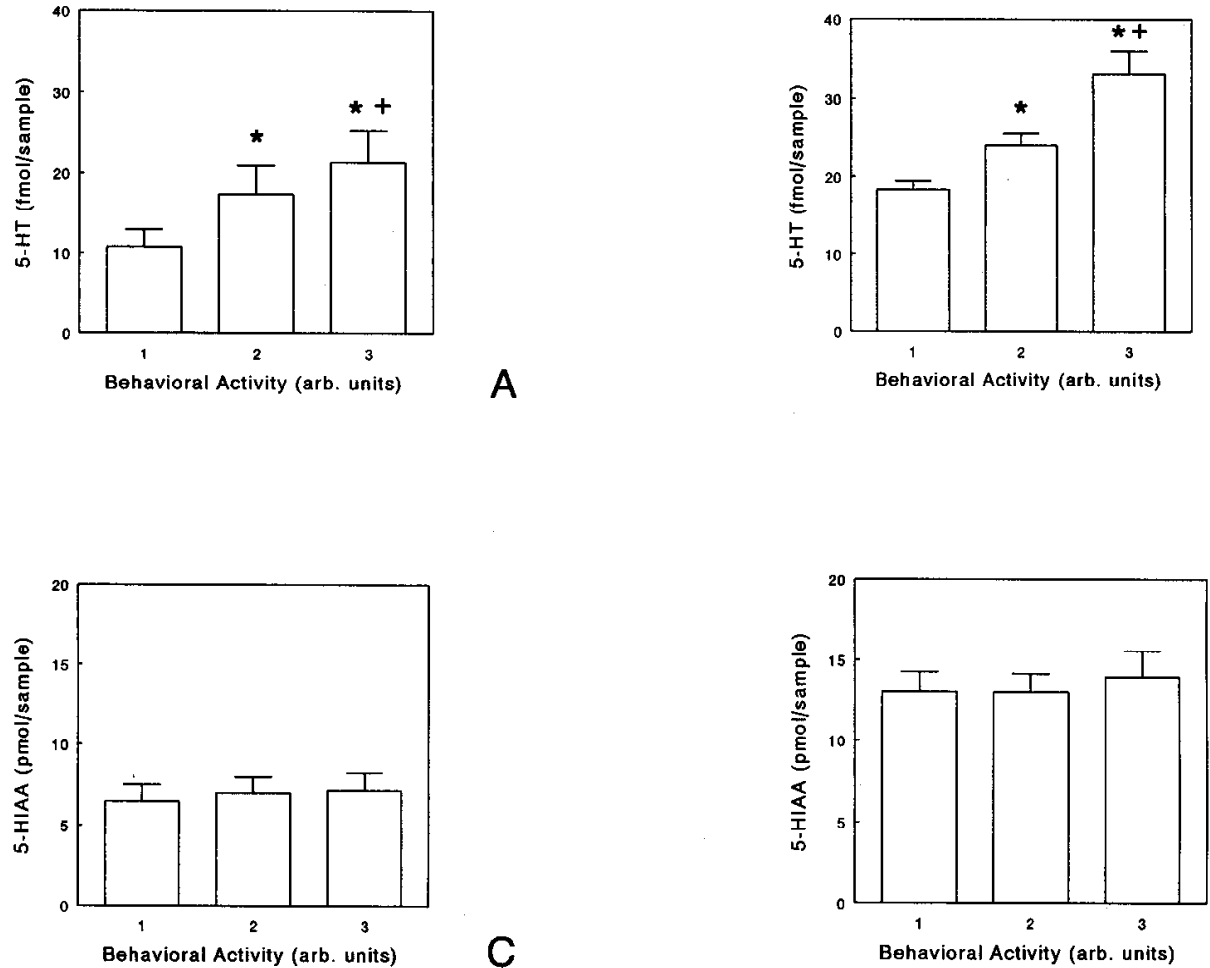

$\mathrm{D}$ were collected between $900-1130 \mathrm{hr}$ for measurement of basal concentrations of 5-HT, 5-HIAA, and corticosterone, after which rats received one i.c.v. injection and one i.p. injection separated by $6 \mathrm{~min}$. The rats were divided into four groups. The first group received an i.c.v. injection of sterile, pyrogen-free saline $(10 \mu \mathrm{l})$ and an i.p. injection of saline $(1$ $\mathrm{ml} / \mathrm{kg}$ body weight). The second group received first an i.c.v. injection of saline followed by an i.p. injection of LPS $(100 \mu \mathrm{g} / \mathrm{kg}$ body weigh diluted to a volume of $1.0 \mathrm{ml} / \mathrm{kg}$ body weight). The third group was first injected i.c.v. with IL-1ra $(10 \mu \mathrm{g})$ followed by an i.p injection of saline. The fourth group received an i.c.v. injection of IL-1 ra $(10 \mu \mathrm{g})$ followed by an i.p. injection of LPS (100 $\mu \mathrm{g} / \mathrm{kg}$ body weight). After the injections, 30 min samples were collected for another $6 \mathrm{hr}(1130-$ $1730 \mathrm{hr}$ )

\section{Histology}

At the end of the experiments, rats were killed and brains were collected in a $4 \%$ formalin solution. Brains were sectioned horizontally or transversally using a freeze microtome and sections were stained with cresyl violet. The neuroanatomical localization of the microdialysis probe and lateral ventricular cannula was verified by inspection of the sections under a microscope.

\section{In vitro recovery of 5-HT, 5-HIAA, and corticosterone}

A microdialysis probe was placed in a vial with a Ringer solution $\left(37^{\circ} \mathrm{C}\right)$ containing defined concentrations of 5-HT, 5-HIAA, and corticosterone. The probe was perfused with Ringer solution at a flow rate of $2 \mu \mathrm{l} /$ min. Dialysate samples were collected every $15 \mathrm{~min}$ and the substances measured according to the methods described below. The in vitro recovery (defined as the concentration in the dialysate divided by the concentration in the in vitro test solution) was $41.1 \% \pm 2.3 \%, 41.8 \%$ $\pm 2.3 \%$, and $41.4 \% \pm 2.9 \%$ (mean \pm SEM, $n=6$ ) for 5 -HT, 5-HIAA, and corticosterone, respectively.

\section{Measurement of 5-HT and 5-HIAA}

Samples were assayed for 5-HT and 5-HIAA without prior purification using HPLC with electrochemical detection. The HPLC apparatus consisted of a Waters 460 pump (Millipore Corporation, Milford, MA), a Rheodyne injection valve (Rheodyne 7125), an Antec Electrochemical Detector (Antec Leyden B.V., Leiden, The Netherlands), and a Chromatography Data System (Thermochrom Model II, LDC Analytical, Riviera Beach, FL). 5-HT and 5-HIAA were separated in a single run by reversed-phase ion-pair chromatography with a Supelcosil-packed column (LC-18-DB, $150 \mathrm{~mm} \times 4.6 \mathrm{~mm}$, particle size $3 \mu \mathrm{m}$; Supelco, Bellefonte, PA). The flow rate was set at $1 \mathrm{ml} / \mathrm{min}$ and the working pressure was $225-250$ bar. The temperature was equal to the ambient temperature. The mobile phase consisted of $18 \%$ methanol, $75 \mathrm{~mm}$ sodium phosphate $\left(\mathrm{NaH}_{2} \mathrm{PO}_{4}\right), 0.2 \mathrm{mM}$ sodium octyl sulfate, $0.1 \mathrm{mM}$ EDTA, and was adjusted to $\mathrm{pH} 4.30$ with phosphoric acid. 5-HT and 5-HIA $\Lambda$ were quantified by electrochemical detection with the detector potential set at $600 \mathrm{mV}$ against an $\mathrm{Ag} / \mathrm{AgCl}$-reference electrode. Calculation of the amounts was based on a standard curve derived from seven reference standards containimg defined quantities. The detection limits for 5-HT and 5-HIAA were between 0.5 and 0.8 fmol per sample at a signal-to-noise ratio of 3 .

\section{Measurement of corticosterone in the dialysates}

Microdialysis samples were assayed for corticosterone by RIA (ICN Biomedicals, Costa Mesa, CA). From the samples, $30 \mu l$ was taken and measured without prior dilution. Apart from the standard curve for plasma samples as supplied with the RIA kit, a separate standard curve was generated for the dialysates. The inter- and intra-assay coefficient of variance was $7 \%$ and $4 \%$, respectively, with a detection limit of 0.005 $\mu \mathrm{g} / 100 \mathrm{ml}$ for the microdialysis samples. Basal levels of corticosterone in the dialysates were very low, but above the detection limit of the assay.

Figure 2. Effects of i.p. administration of saline and different doses of LPS (30, 100, and $300 \mu \mathrm{g} / \mathrm{kg}$ body weight) on hippocampal extracellular concentrations of 5-HT $(A-D)$ and 5-HIAA $(E-H)$, and on behavioral activity $(A-D)$. Samples were collected every 15 min as described under protocol A. The time point of injection is indicated by the urrow. Extracellular levels of 5-HT and 5-HIAA are expressed as percent of baseline (for definition of "baseline," see Calculations and statistical procedures in Materials and Methods) and are depicted as triangles in the respective figures. The corresponding behavioral activity scores (expressed as arbitrary units; see Experimental protocols in Materials and Methods) are depicted as bars in $A-D$. Time points on the x-axis correspond with the time at which collection of the respective sample was started. Values represent means \pm SEM (saline group, $n=5$; LPS groups, $n=6$ ). 

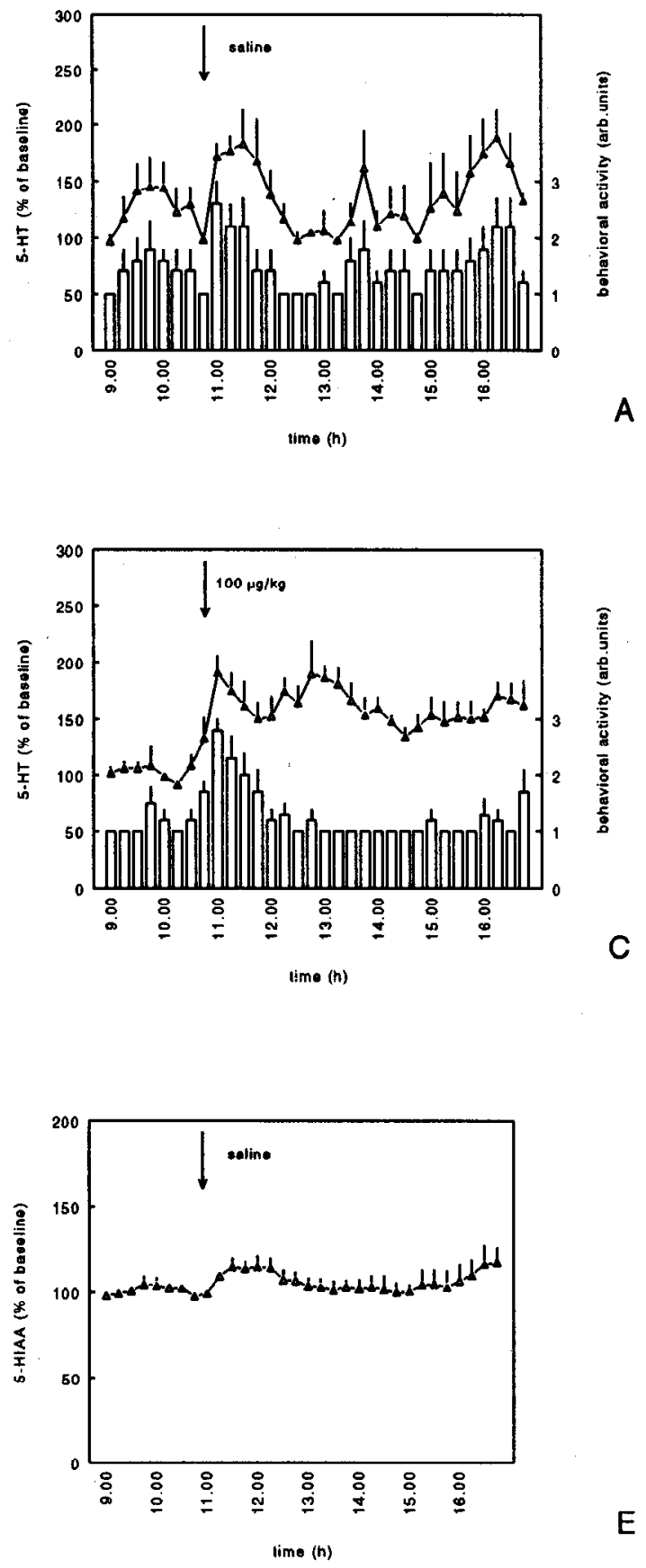

E

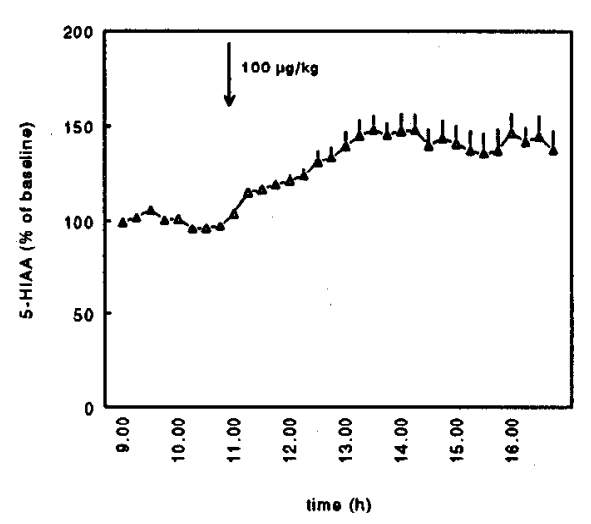

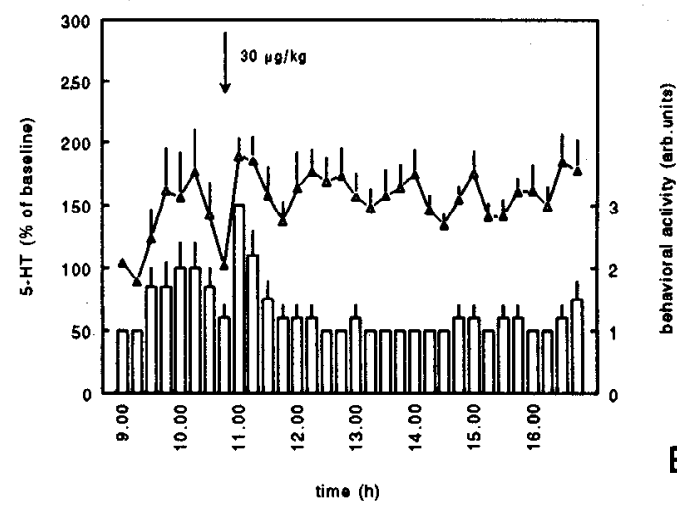
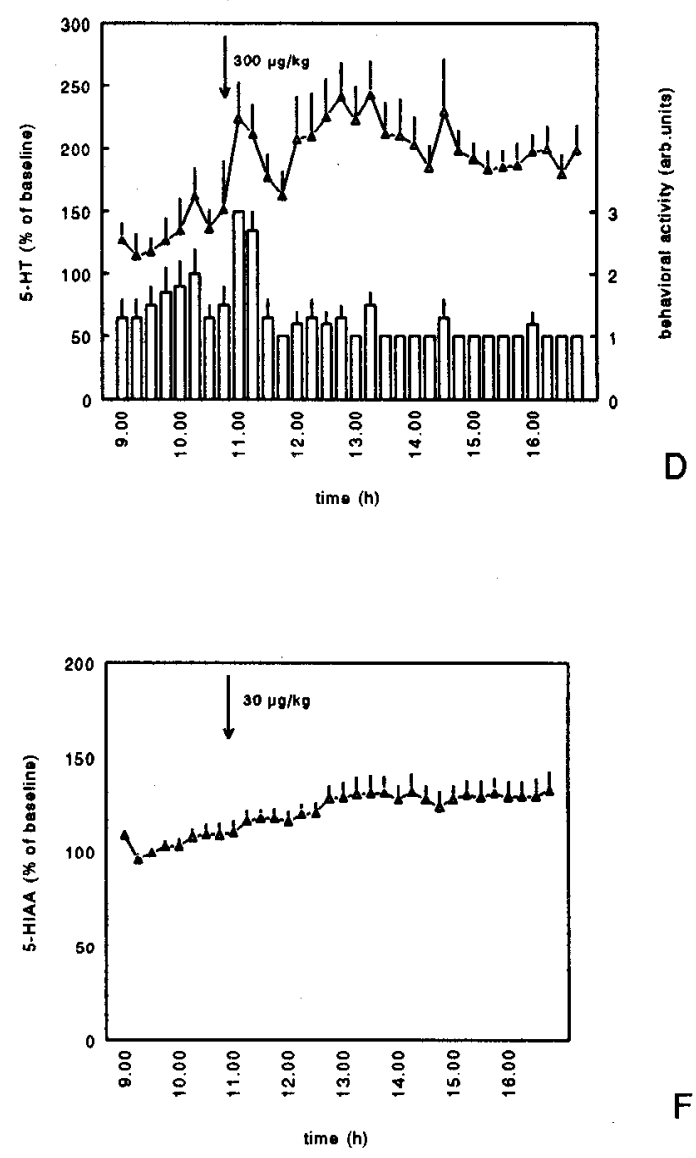

F

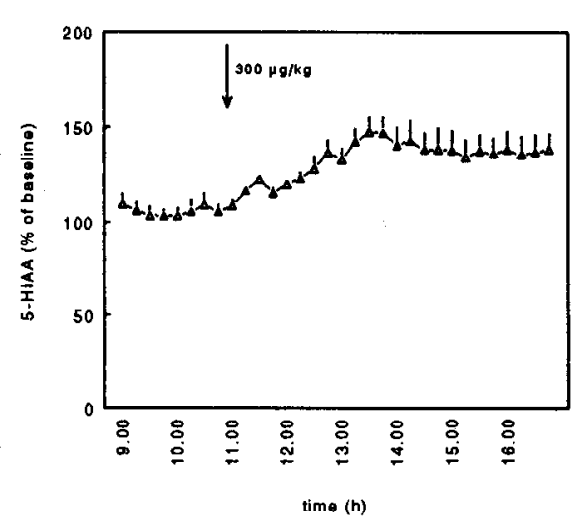

H 

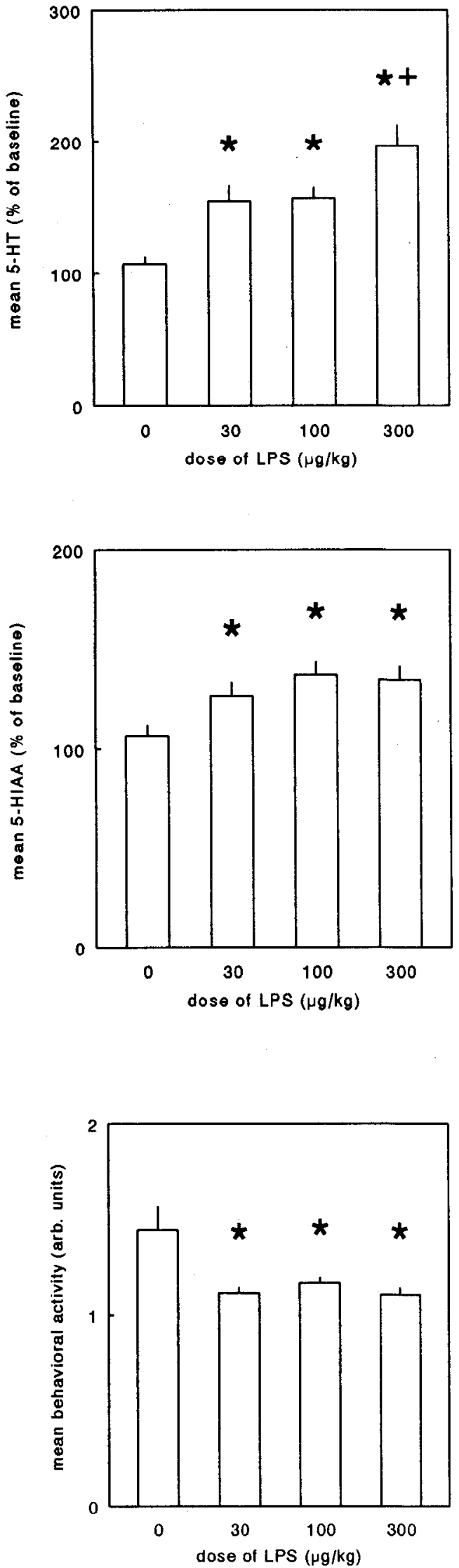

Figure 3. Mean values of hippocampal extracellular concentrations of 5-HT and 5-HIAA, and of behavioral activity scores for the period after the i.p. injection of saline or different doses of LPS (30, 100, and 300 $\mu \mathrm{g} / \mathrm{kg}$ body weight) as deducted from the time curves in Figure 2.

\section{Materials}

Recombinant hIL-1 $\beta$ and IL-1ra were gifts of Dr. E. B. De Souza (The DuPont Merck Pharmaceutical Company, Wilmington, DE). LPS ( $\mathrm{Sal}$ monella abortus equi, catalog no. L-6636), sodium octyl sulphate, and reference substances were obtained from Sigma (St. Louis, MO). Methanol was specially prepared for chromatography (Lichrosolv) and was purchased from Merck (Darmstadt, Germany), as were all other chemicals (analytical grade).

\section{Calculations and statistical procedures}

All results are expressed as mean \pm SEM. Baseline extracellular concentrations of 5-HT and 5-HIAA in the hippocampus were calculated by averaging the values obtained at behavioral activity " 1 " in the period before the injection(s). Only data from rats with at least three samples at behavioral activity " 1 " were used for analysis. Next, extracellular concentrations of 5-HT and 5-HIAA were expressed as percentage of baseline for each individual rat. For each control rat (i.p. saline or i.c.v. saline/i.c.v. saline), mean extracellular 5-HT and 5-HIAA concentrations were calculated for each behavioral activity score " 1, , "2," and " 3 ," using data from the whole time curve. Multivariate analysis of variance (MANOVA) with repeated measures design was used to determine whether overall significant differences existed between the extracellular concentrations of 5-HT or 5-HIAA at different behavioral activity scores. If for 5-HT or 5-HIAA a significant main effect of "behavioral activity" was found, an additional trend analysis with polynomial contrasts within MANOVA was performed to obtain the curve form that fits the means of these variables (5-HT, 5-HIAA) with behavioral activity, and paired $t$ tests were done to assess separate statistical differences between 5-HT or 5-HIAA levels at their respective behavioral activity scores.

MANOVA with repeated measures design was also used to evaluate the effects of LPS, hIL-1 $\beta$, and IL-1ra on extracellular concentrations of 5-HT and 5-HIAA, free corticosterone, and behavioral activity, using treatment as the between-subject factor and time as the within-subject factor. Then, mean values for the period after the injection(s) were calculated for the different parameters. For 5-HT, only values obtained at behavioral activity score " 1 " were used. Analysis of variance (ANOVA) including the post hoc comparisons of Duncan was used to test statistical differences for these parameters (5-HT, 5-HIAA, corticosterone in the dialysate, and behavioral activity) between the experimental groups. The first half-hour after the injection(s) was not included in these analyses to avoid interference of any (stress-induced) acute changes in the parameters occurring after the injection(s).

As level of significance, $\alpha=0.05$ was accepted. This was corrected by Bonferroni procedure when multiple comparisons were performed.

\section{Results}

Serotonergic neurotransmission in the hippocampus in relation to behavioral activity

The relationship between serotonergic neurotransmission in the hippocampus and behavioral activity was analyzed in control rats of protocol A (15 min sampling time) and C (30 min sampling time). In control rats (i.p. saline or i.c.v. saline/i.c.v. saline), a significant relationship between extracellular 5-HT levels and behavioral activity was evident (Fig. 1A,B; see also Figs. $2 A, 4 A, 5 A, 7 A$ ). Thus, hippocampal extracellular 5-HT levels rose in parallel with increasing behavioral activity [MANOVA control rats of protocol A: $F(2,8)=21.4$, significance of $F=$ 0.001 ; polynomial contrast: linear trend, $t=5.7$, significance of $t=0.005$; MANOVA control rats of protocol C: $F(2,8)=30.1$,

$\leftarrow$

Samples were collected every $15 \mathrm{~min}$ as described under protocol $\mathrm{A}$. Extracellular levels of 5-HT and 5-HIAA are expressed as percent of baseline (for definition of "baseline," see Calculations and statistical procedures in Materials and Methods). The behavioral activity scores are expressed as arbitrary units (see Experimental protocols in Materials and Methods). *, significantly different from control rats; + , significantly different from rats treated with 30 or $100 \mu \mathrm{g} / \mathrm{kg}$ LPS (Duncan multiple range test). 

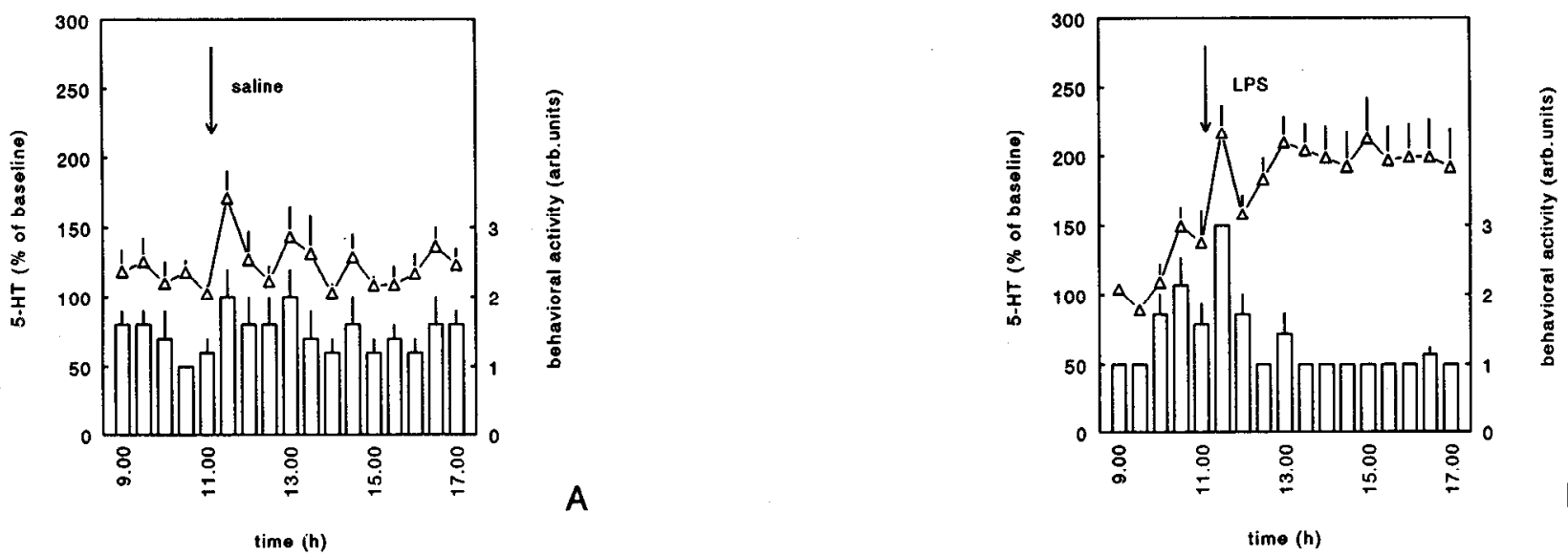

B
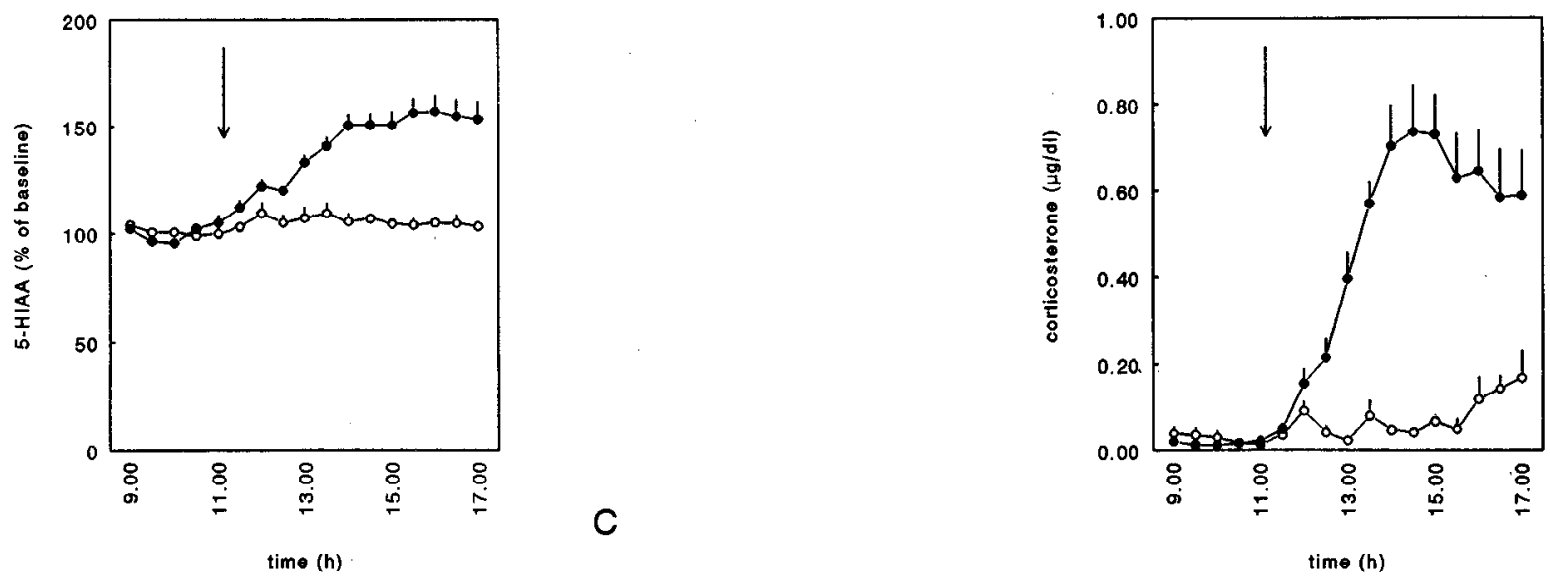

Figure 4. Effects of i.p. administration of saline $(A)$ and $100 \mu \mathrm{g} / \mathrm{kg}$ LPS $(B)$ on hippocampal extracellular concentrations of 5-HT and on behavioral activity. Fxtracellular levels of 5-HT are expressed as percent of baseline (for definition of "baseline," see Calculations and statistical procedures in Materials and Methods) and are depicted as triangles. The corresponding behavioral activity. scores (expressed as arbitrary units; see Experimental protocols in Materials and Methods) are depicted as bars. $C$ and $D$ represent the effect of $100 \mu \mathrm{g} / \mathrm{kg}$ LPS (closed circles) or saline (open circles) on 5-HIA $\wedge$ (expressed as percent of baseline) and dialysate corticosterone (in $\mu \mathrm{g} / \mathrm{dl}$ ), respectively. Samples were collected every $30 \mathrm{~min}$ as described under protocol B. The time point of injection is indicated by the arrow. Time points on the X-axis correspond with the time at which collection of the respective sample was started. Values represent means \pm SEM of six rats. LPS significantly increased extracellular concentrations of 5-HT [MANOVA with repeated measures, effect of treatment: $F(1,10)-9.2$, significance of $F \leq 0.020$ ] and decreased behavioral activity [MANOVA with repeated measures, effect of treatment: $F(1,10)=4.5$, significance of $F=0.001]$ when compared to saline-treated controls. LPS significantly increased extracellular concentrations of 5-HIAA [MANOVA with repeated measures, effect of treatment: $F(1,10)=46.3$, significance of $F \leq$ 0.0005 ] and corticosterone [MANOVA with repeated measures, effect of treatment: $F(1,10)=38.5$, significance of $F \leq 0.0005$ ] when compared to saline-treated controls.

significance of $F \leq 0.0005$; polynomial contrast: linear trend, $t$ $=7.2$, significance of $t=0.002]$. A similar relationship was also found in control rats of protocol B and D (see Figs. $4 A$, $7 A)$.

No significant relationship between extracellular 5-HIAA levels and behavioral activity was found [Fig. 1C,D; MANOVA control rats of protocol A: $F(2,8)=4.2$, significance of $F>$ 0.05 ; MANOVA control rats of protocol C: $F(2,8)=2.6$, significance of $F>0.05$ ].

\section{Effect of LPS on serotonergic neurotransmission in the hippocampus (protocol A)}

I.p. injection of LPS caused a significant, dose-dependent increase in extracellular 5-HT levels in the hippocampus [MAN-
OVA with repeated measures: effect of treatment $F(3,19)=4.9$, significance of $F<0.02$; interaction treatment $\times$ time: $F(63,399)=1.4$, significance of $F<0.05$; Figs. $2 A-D, 3 A]$. Peripherally administered LPS produced not only an increase in the parent indoleamine, but a significant rise in the extracellular concentrations of its main metabolite 5-HIAA was observed as well [MANOVA with repeated measures, effect of treatment: $F(3,18)=4.3$, significance of $F<0.02$; interaction treatment $\times$ time: $F(63,378)=2.2$, significance of $F \leq 0.0005$; Figs. $2 E, F ; 3 B]$. The dose dependency of the effect of LPS on 5-HIAA levels was not as evident as that of the effect of LPS on 5-HT concentrations (Fig. 3A,B).

While in rats injected i.p. with saline a close relationship between 5-HT and behavioral activity was observed (see above), 

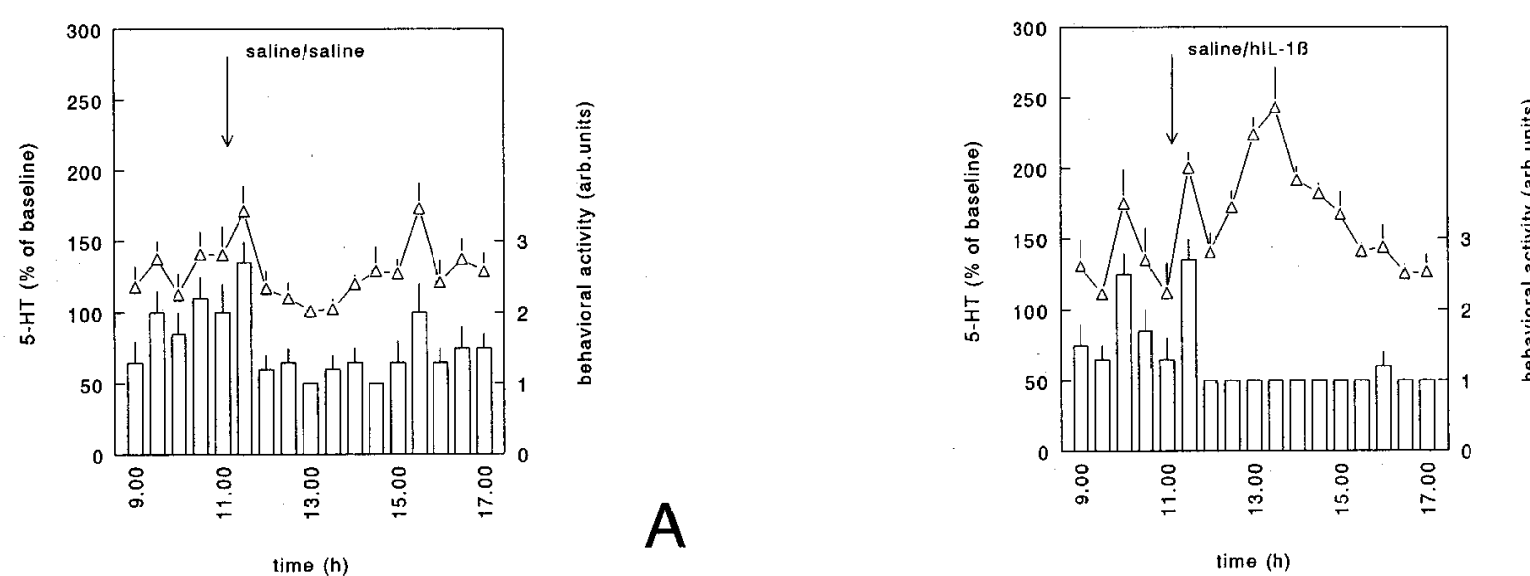

B
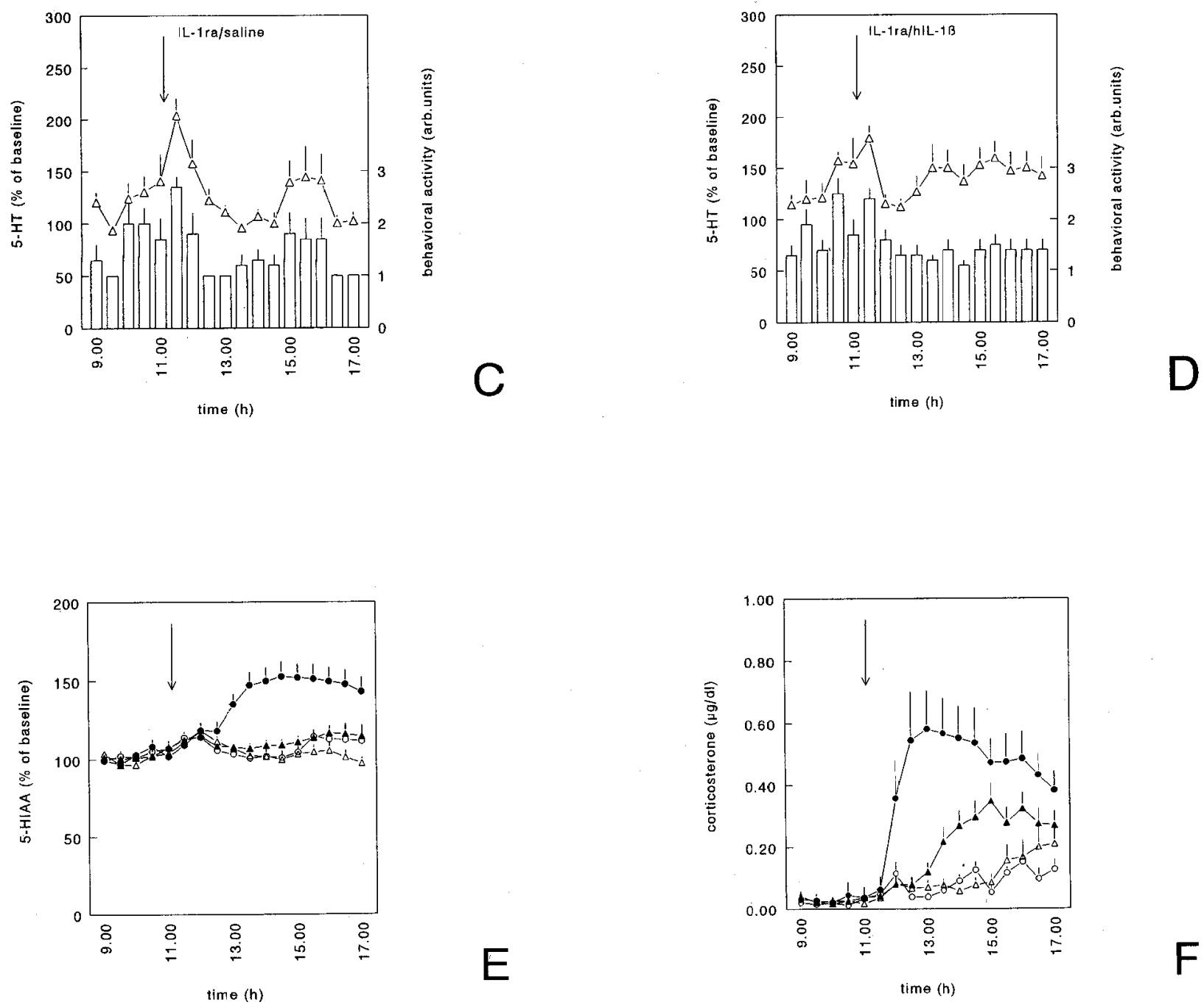

Figure 5. Effects of i.c.v. administration of hIL-1 $\beta(B)$ and i.c.v. pretreatment with IL-1ra $(D)$ on hippocampal extracellular concentrations of 5-HT and behavioral activity. The results obtained in the respective control groups, saline/saline- and IL-1ra/saline-treated rats, are shown in $A$ and C. Extracellular levels of 5-HT are expressed as percent of baseline (for definition of "baseline," see Calculations and statistical procedures in Materials and Methods) and are depicted as open triangles. The corresponding behavioral activity scores (expressed as arbitrary units; see Experimental protocols in Materials and Methods) are depicted as bars. Values represent means \pm SEM $(A-C$ : for 5-HT and behavioral activity, $n=6$; 
rats injected with LPS showed no increase in behavioral activity in parallel with rising 5-HT concentrations. Actually, in these rats a significant decrease in behavioral activity was found [MANOVA with repeated measures, effect of treatment $F(3,19)$ $=6.7$, significance of $F<0.01$; Figs. $2 A-D, 3 C$ ). This decline in behavioral activity did not appear to depend on the dose of LPS (Fig. 3C).

\section{Effect of LPS on free corticosterone levels as measured by in vivo microdialysis (protocol $B$ )}

As shown in Figure $4 A-C$, using protocol B (30 min samples; LPS $100 \mu \mathrm{g} / \mathrm{kg}$ ), LPS produced similar effects on serotonergic neurotransmission and behavioral activity as found in the experiments using protocol A (for statistics, see legend to Fig. 4). 5-HT levels started to increase between 60-90 min after injection of LPS and reached their maximum between 90-120 min after the injection (Fig. 4B). 5-HIAA levels showed a significant increase between $60-90 \mathrm{~min}$ and reached a maximum after 150$180 \mathrm{~min}$ (Fig. 4C). In this protocol, dialysate samples were also assayed for corticosterone. Since the extracellular space is devoid of corticosterone binding proteins (e.g., corticosterone binding globulin, albumin), the corticosterone levels in the dialysate are a reflection of the biologically active "free" corticosterone fraction. As shown in Figure $4 D$, corticosterone levels in the dialysates of rats injected i.p. with saline showed a distinct diurnal rhythm, with low levels during the first part of the light period and a marked rise starting between 1600 and $1630 \mathrm{hr}$. I.p. injection of LPS $(100 \mu \mathrm{g} / \mathrm{kg})$ produced a pronounced increase in corticosterone levels as compared to the controls, which attained statistical significance in the third sample after the injection (between 60-90 min after the injection) [MANOVA with repeated measures, effect of treatment: $F(1,10)=38.5$, significance of $F \leq 0.0005$; interaction of treatment $\times$ time: $F(10,100)=6.1$, significance of $F \leq 0.0005$ ]. Maximal levels of corticosterone were reached between 150-180 min after injection of $100 \mu \mathrm{g} / \mathrm{kg}$ LPS. Hence, although all levels started to increase between 60-90 min after administration of LPS, the extracellular levels of 5-HIAA and corticosterone reached their maximum about $60 \mathrm{~min}$ later than the extracellular concentrations of 5-HT (Fig. 4B-D).

\section{Effect of i.c.v. hIL-1 $\beta$ and IL-Ira on hippocampal serotonergic neurotransmission, behavioral activity, and free corticosterone levels (protocol C)}

Figure 5 shows the time course of the effect of i.c.v.-applied hIL-1 $\beta$ and IL-1ra on extracellular concentrations of 5-HT, 5-HIAA, corticosterone, and behavioral activity, and Figure 6 shows the mean values of these parameters after the injection. For all four parameters, a significant main effect of treatment was found [MANOVA with repeated measures, 5-HT: $F(3,21)$ $=7.0$, significance of $F<0.01 ; 5$-HIAA: $F(3,24)=16.7$, significance of $F \leq 0.0005$; behavioral activity: $F(3,24)-3.6$, significance of $F<0.05$; corticosterone: $F(3,24)=10.2$, sig- nificance of $F \leq 0.0005]$ as well as, except for behavioral activity, a significant interaction treatment $x$ time [5-HT: $F(30,210)=4.4$, significance of $F \leq 0.0005 ; 5$-HIAA: $F(30,240)=4.3$, significance of $F \leq 0.0005$; corticosterone: $F(30,240)=5.2$, significance of $F \leq 0.0005]$. I.c.v. administration of $100 \mathrm{ng}$ hIL-1 $\beta$ caused a marked transicnt increase in hippocampal extracellular 5-HT concentrations (Figs. 5B, 6A). Levels started to increase 60-90 min after the injection, reached a maximum of $150 \%$ above baseline after $90-120 \mathrm{~min}$, and returned to baseline about $60 \mathrm{~min}$ before end of the experiment (Fig. $5 B$ ). hIL-1 $\beta$ also raised extracellular concentrations of 5-HIAA starting between 90-120 min after the injection, reaching a maximum of about 50\% above baseline after $120-150 \mathrm{~min}$, and remained elevated up to the end of the experiment (Figs. $5 E, 6 B)$. In rats treated i.c.v. with hIL- $1 \beta$, a significant decrease in behavioral activity was observed (Figs. $5 B, 6 C$ ). Rats displayed several characteristics reminiscent of sickness, for example, piloerection, curled body posture, and immobility. I.c.v. administration of hIL- $1 \beta$ caused a dramatic rise in free corticosterone levels starting between $30-60 \mathrm{~min}$ after the injection and reaching a maximum after 60-90 min (Figs. 5F, 6D).

I.c.v. injection of $10 \mu \mathrm{g} \mathrm{IL} 1 \mathrm{ra}$ had no effects on the parameters measured in this study (Figs. $5 C, E, F ; 6$ ). However, IL-1 ra antagonized the stimulating effects of hIL-1 $\beta$ on hippocampal serotonergic neurotransmission, behavioral activity, and corticosterone levels (Figs. $5 D-F, 6$ ). There were no statistically significant differences in these parameters between the rats treated with hIL-1 $\beta$ after pretreatment with IL-1 ra and the saline/salineand IL-1ra/saline-treated rats. However, careful inspection of Figure $5 F$ may suggest that after pretreatment with $10 \mu \mathrm{g} \mathrm{IL}$ $1 \mathbf{r a}, \mathrm{hII}-1 \beta$ is still able to produce a small, time-delayed increase in free corticosterone levels, which, however, was not statistically significant.

\section{Effect of i.c.v. pretreatment with IL-Ira on LPS-induced changes in serotonergic neurotransmission, behavioral activity, and free corticosterone levels (protocol D)}

Figure 7 shows the time course of the effect of i.c.v.-administered IL-1 ra on LPS-induced changes in extracellular concentrations of 5-HT, 5-HIAA, corticosterone, and behavioral activity. In Figure 8, the mean values of these parameters after the injections are shown. For all four parameters a significant main effect of trealnent was found [MANOVA with repeated measures using all four treatment groups, 5-HT: $F(3,21)=14.7$, significance of $F<0.0005 ; 5$-HIAA: $F(3,21)=42.8$, significance of $F \leq 0.0005$; behavioral activity: $F(3,21)=15.2$, significance of $F \leq 0.0005$; corticosterone: $F(3,21)=27.5$, significance of $F \leq 0.0005$ ) as well as, except for behavioral activity, a significant interaction treatment $\times$ time [5-HT: $F(30,210)=1.7$, significance of $F<0.02 ; 5$-HIAA: $F(30,210)$ $=11.5$ significance of $F \leq 0.0005$; corticosterone: $F(30,210)=$ 8.2, significance of $F \leq 0.0005$ ]. Similar to the results described under protocols A and B, i.p. injection of LPS caused a signif-

$D$ : for hehavioral activity, $n=10$, but for $5-\mathrm{HT}, n=7$, since in three rats 5 -HT could not be measured due to chromatographic problems). $E$ and $F$ represent the effects of i.c.v. administration of hIL-1 $\beta$ and of i.c.v. pretreatment with IL-1 ra on hippocampal extracellular concentrations of 5-HIAA (percent of baseline, mean \pm SEM) and dialysate corticosterone ( $\mu \mathrm{g} / \mathrm{dl}$, mean \pm SEM), respectively. Regarding these paradigms $(5$-HIAA and corticosterone), the four experimental groups are depicted as follows: i.c.v. salinc/i.c.v. salinc-trcatcd rats, open circles $(n=6)$; i.c.v. saline/ i.c.v. hIL-1 $\beta$-treated rats, closed circles $(n=6)$; i.c.v. IL-1 ra/i.c.v. saline-treated rats, open triangles $(n=6)$; i.c.v. IL-1ra/i.c.v. hIL-1 $\beta$-treated rats, closed triangles $(n=10)$. Samples were collected every $30 \mathrm{~min}$ as described under protocol $\mathrm{C}$. The time point of the injections is indicated by the arrow (i.c.v. injection followed 6 min after i.c.v. pretreatment). Time points on the x-axis correspond with the time at which collection of the respective sample was started. 


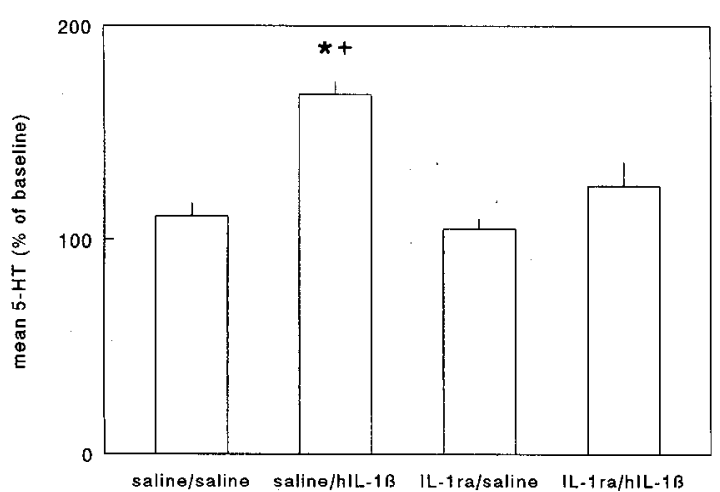

A

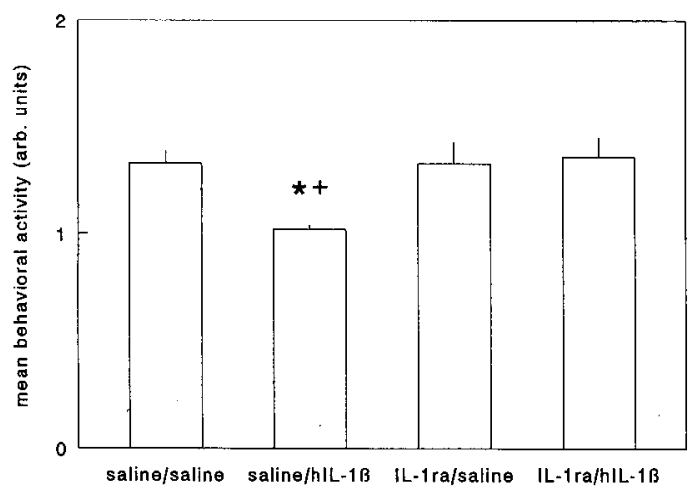

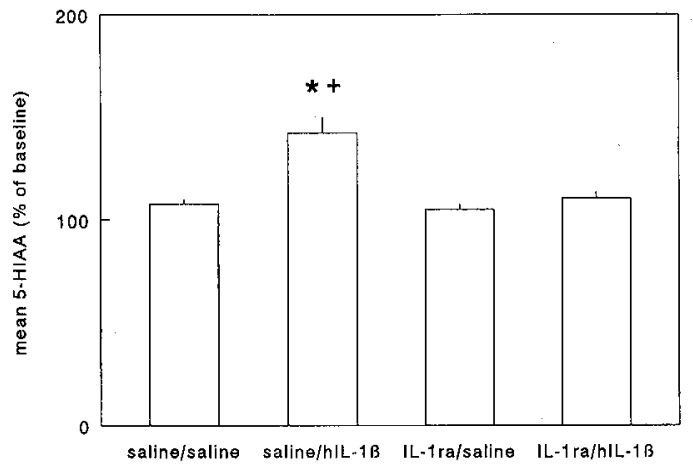

B

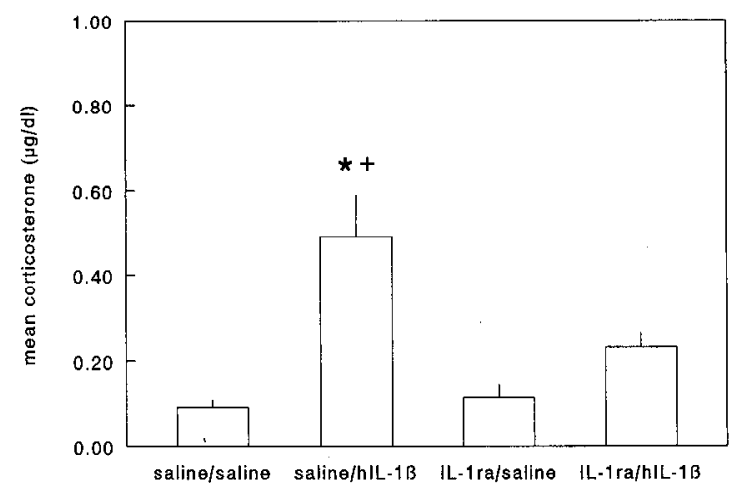

C

Figure 6. Mean values of hippocampal extracellular concentrations of 5-HT $(A), 5$-HIAA $(B)$, and dialysate corticosterone $(D)$, and of behavioral activity scores $(C)$ for the period after i.c.v. treatment with saline or hIL-1 $\beta$ and i.c.v. pretreatment with saline or IL-lra as deducted from the time curves presented in Figure 5. There were four experimental groups: i.c.v. saline/i.c.v. saline-, i.c.v. saline/i.c.v. hIL-1 $\beta-$, i.c.v. IL-1ra/i.c.v. saline-, and i.c.v. IL-1ra/i.c.v. hIL-1 $\beta$-treated rats. Samples were collected every $30 \mathrm{~min}$ as described under protocol C. Extracellular levels of 5-HT and 5-HIAA are expressed as percent of baseline (for definition of "baseline," see Calculations and statistical procedures in Materials and Methods). The behavioral activity scores are expressed as arbitrary units (see Experimental protocols in Materials and Methods). Corticosterone concentrations are expressed as $\mu \mathrm{g} / \mathrm{dl} .{ }^{*}$, significantly different from its respective control group; + , significantly different from IL-1 ra/hIL-1 $\beta$-treated rats (Duncan multiple range test).

icant increase in extracellular levels of 5-HT, 5-HIAA, and corticosterone, and a significant decrease in behavioral activity. The time courses of the effects observed in protocol D were similar to those found in protocol A and B (Figs. 2, 4, 7). I.c.v. injection of $10 \mu \mathrm{g} \mathrm{IL}-1$ ra produced no effects on the parameters measured in this study (Figs. $7 C, E, F ; 8$ ). I.c.v. pretreatment with IL-1ra did not antagonize the effects of LPS on free corticosterone levels and behavioral activity (Figs. $7 D, F ; 8 C, D$ ). However, i.c.v.administered IL-1ra significantly attenuated the LPS-induced rise in hippocampal extracellular levels of 5-HT (Figs. 7D, 8A). There was also a small reduction in the effect of LPS on hippocampal extracellular levels of 5-HIAA after i.c.v. pretreatment with IL-1 ra, although this attenuation did not reach statistical significance (Figs. $7 E, 8 B$ ).

\section{Discussion}

The present study shows, using an in vivo microdialysis method, that i.p. administration of LPS causes an increase in the extracellular concentrations of 5-HT and its metabolite 5-HIAA in the rat hippocampus in combination with a decrease in behavioral activity and a profound increase in extracellular corticosterone levels. I.c.v. application of the cytokine hIL-1 $\beta$ largely mimicked the effects of LPS on serotonergic neurotransmission, behavioral activity, and corticosterone levels. The effects of hIL$1 \beta$ could be antagonized by i.c.v. pretreatment with IL-1ra. In addition, i.c.v. pretreatment with IL-1ra attenuated the increase in hippocampal extracellular concentrations of 5-HT after peripheral administration of LPS. These results suggest that the hippocampus participates in CNS responses to an immune stimulus. Moreover, our data suggest that a central action of IL-1 is involved in the changes in hippocampal 5-HT after peripheral immune stimulation.

We report here the existence of a significant relationship between behavioral activity and extracellular concentrations of 5-HT in the hippocampus of rats. Changes in behavioral activity were paralleled by alterations in 5-HT concentration as evidenced by the almost $100 \%$ increase in $5-\mathrm{HT}$ levels in relatively active rats (behavioral activity score 3 ) compared to inactive 
animals (behavioral activity score 1). A similar relationship was also found in the neocortex (Linthorst et al., 1994) and preoptic area of rats (Linthorst and Reul, unpublished observations). These results are in good agreement with the higher mean hippocampal 5-HT levels in rats during the dark (active) period as compared to the light period of the day (Kalén et al., 1989), and with electrophysiological studies showing a positive correlation between the single-unit activity of serotonergic neurons in the raphe nuclei and the level of behavioral arousal of animals (Trulson and Jacobs, 1979; for extensive review see Jacobs and Azmitia, 1992). For this reason, it is of utmost importance to include data on the behavioral activity of animals when studying the effects of physiological/pharmacological manipulation on brain serotonergic neurotransmission.

I.p. administration of LPS and i.c.v. administration of hIL-1 $\beta$ caused marked increases in hippocampal extracellular concentrations of 5-HT and 5-HIAA, and a decrease in behavioral activity. Thus, unlike the situation in saline-treated rats, the close correlation between 5-HT levels and behavioral activity appeared to be disrupted in the endotoxin- and hIL-1 $\beta$-treated animals. This dissociation may be unique for the effects of immune stimulation on the hippocampal serotonergic system, since in the literature no such dissociation after several manipulations has been described so far (for review see Azmitia and Jacobs, 1992). Wilkinson et al. (1991) found that the immunostimulant muramyl dipeptide did not alter extracellular levels of serotonin in the hypothalamus of the cat. However, it was observed that variations in extracellular hypothalamic levels of serotonin were dependent on the behavioral state of the animal (Wilkinson et al., 1991). Moreover, gentle handling or tail pinch in rats has been reported to alter hippocampal 5-HT levels solely in parallel with behavioral activity (Kalén et al., 1989).

In several physiological systems, such as growth hormone release (Rettori et al., 1987; Payne et al., 1992) and sleep (Opp et al., 1991), IL-1 has been described to exert distinct dose-dependent effects. Although only one dose of hIL- $1 \beta$ has been used in the present study, the i.c.v.-administered interleukin produced effects on hippocampal serotonergic neurotransmission similar to i.p.-injected LPS. Nevertheless, it cannot be excluded that hIL-1 $\beta$ administered in other doses could produce different effects on hippocampal serotonergic neurotransmission.

Woodroofe and coworkers (1991) have described increased levels of dialysate IL- 1 between 24 and $48 \mathrm{hr}$ after implantation of a U-shaped microdialysis probe in the brain. The experiments described in our study were started between $40-45 \mathrm{hr}$ after implantation. Although a possible involvement of endogenously released IL-1 after implantation of a microdialysis probe cannot be excluded, we found that i.c.v. administration of IL-1ra showed neither intrinsic nor antagonistic effects on any of the parameters under study here. Therefore, it may be concluded that, under our experimental conditions, endogenous IL-1 release may be too low to significantly influence hippocampal extracellular levels of 5-HT and 5-HIAA, corticosterone levels, and behavioral activity.

Rada et al. (1991) showed that the hippocampal cholinergic system is also responsive to IL-1, as indicated by the decreased levels of acetylcholine in hippocampal dialysates after i.p. application of IL-1 $\beta$. Direct effects of IL-1 on hippocampal neurons using electrophysiological approaches have been described as well (Katsuki et al., 1990; Plata-Salamán and FFrench-Mullen, 1992; Zeise et al., 1992). Several research groups have reported increases in serotonergic turnover (as derived from post- mortem tissue levels) in brain areas other than the hippocampus, such as hypothalamus (Mefford et al., 1990; Dunn and Vickers, 1994) and cortex (Dunn, 1992a; Gardier et al., 1994), after immune stimulation and/or peripheral administration of IL-1. However, Wilkinson et al. (1991) found no effect of muramyl dipeptide on feline hypothalamic serotonergic neurotransmission. In vivo application of IL-1 directly into the hypothalamus produced increased levels of 5-HIAA (Mohankumar et al., 1993; Shintani et al., 1993) and 5-HT (Shintani et al., 1993), although by use of a superfusion technique a decreased in vitro release of 5-HT from the hypothalamus was observed (Palazzolo and Quadri, 1992). I.c.v. administration of IL-1 has been reported to increase 5-HIAA levels in the hypothalamus in vivo (Gemma et al., 1991). In addition, immune stimulation and administration of IL-1 (peripherally, centrally, or in the incubation medium) have been described to exert distinct effects on other neurotransmitter systems, as assessed by measurement of postmortem levels of neurotransmitters and their metabolites (Kabiersch et al., 1988; Dunn, 1988, 1992a,b; Mefford et al., 1990; Dunn and Vickers, 1994; Zalcman et al., 1994) and by using in vivo (Mohankumar et al., 1991; Mohankumar and Quadri 1993; Shintani et al., 1993) and in vitro (Miller et al., 1991; Sawada et al., 1992) techniques. Our in vivo study describes the effects of peripheral immune stimulation on hippocampal serotonergic neurotransmission and as such contributes to delineate the neural circuits involved in the communication between the immune system and a higher limbic brain structure.

In the present study, both i.p. LPS and i.c.v. hIL-1 $\beta$ raised free corticosterone lcvels, indicating a profound activation of the HPA axis. These results are in good agreement with literature data showing increases in plasma corticosterone levels after immune stimulation and peripheral as well as i.c.v. injection of IL-1 in different species (for review see Besedovsky and Del Rey, 1992). It has been found that one of the mechanisms by which IL-1 stimulates the HPA axis on the level of the brain is via the stimulation of corticotropin-releasing hormone (CRH) secretion in the hypothalamus (Berkenbosch et al., 1987; Sapolsky et al., 1987; Uehara et al., 1987; Tsagarakis et al., 1989; Navarra et al., 1991). However, the involvement of extrahypothalamic brain areas (Ovadia et al., 1989; Linthorst et al., 1994) as well as direct effects of IL-1 on the level of the pituitary and adrenal cortex have also been suggested (for review, see Hermus and Sweep, 1990).

The present study shows that administration of LPS and hIL$1 \beta$ produce basically similar effects on hippocampal extracellular levels of 5-HT and 5-HIAA, corticosterone, and behavioral activity. This observation suggests that IL- $1 \beta$ may be a mediator of the LPS-induced effects. The here-described attenuation of the LPS-induced effect on hippocampal 5-HT by i.c.v. pretreatment with IL-1ra underpins the concept of a central action of IL-1 participating in the effect of a peripheral immune challenge on hippocampal serotonergic neurotransmission. IJowever, several observations strongly suggest the participation of additional factors in the (patho)physiological responses to peripheral inoculation of LPS: (1) the relatively rapid return of 5-HT levels to baseline values after i.c.v. hIL-1 $\beta$ as compared to the prolonged elevation observed after LPS, (2) the only partial attenuation of the LPS effect on serotonergic neurotransmission after i.c.v. IL-1ra, and (3) the absence of any effect of i.c.v. IL-1 ra on changes in corticosterone and behavioral activity after LPS. It has been shown that i.p. and intravenous (i.v.) LPS inoculation in rodents and humans causes the release of IL-1, IL-6, and TNF 


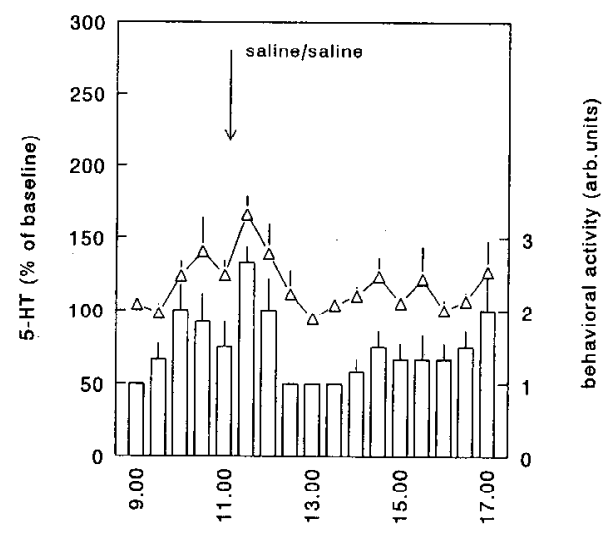

$\operatorname{tim} \theta(h)$
A
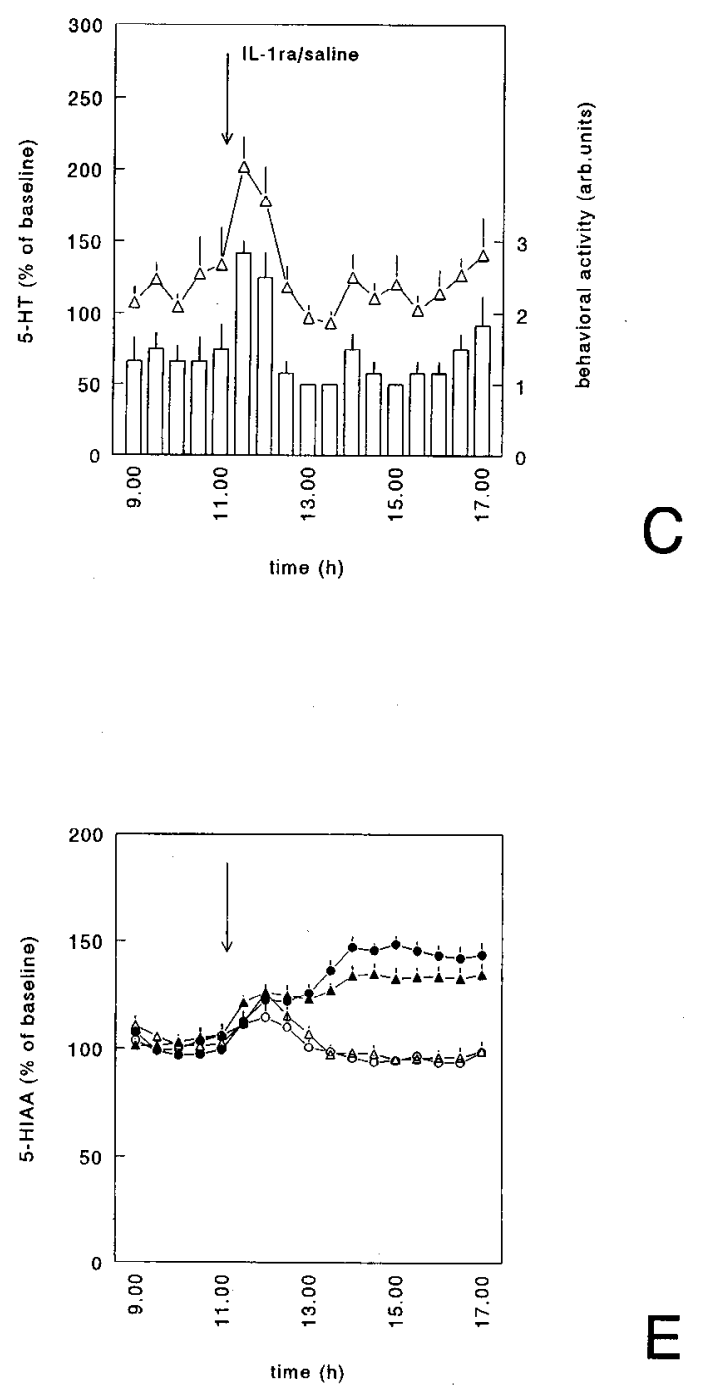

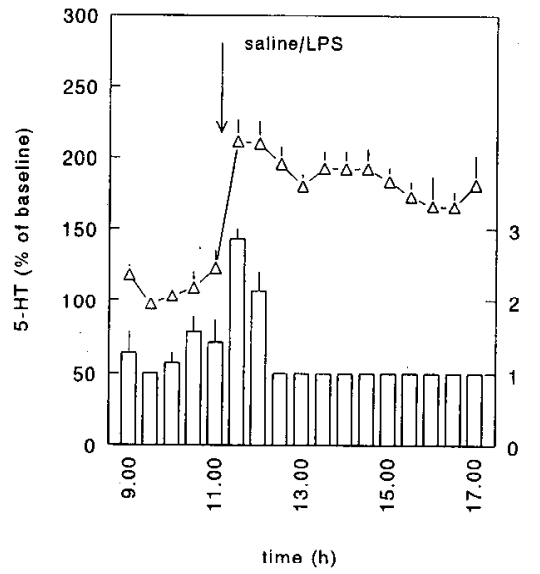

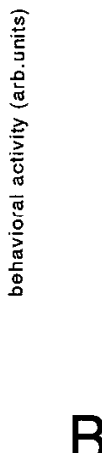
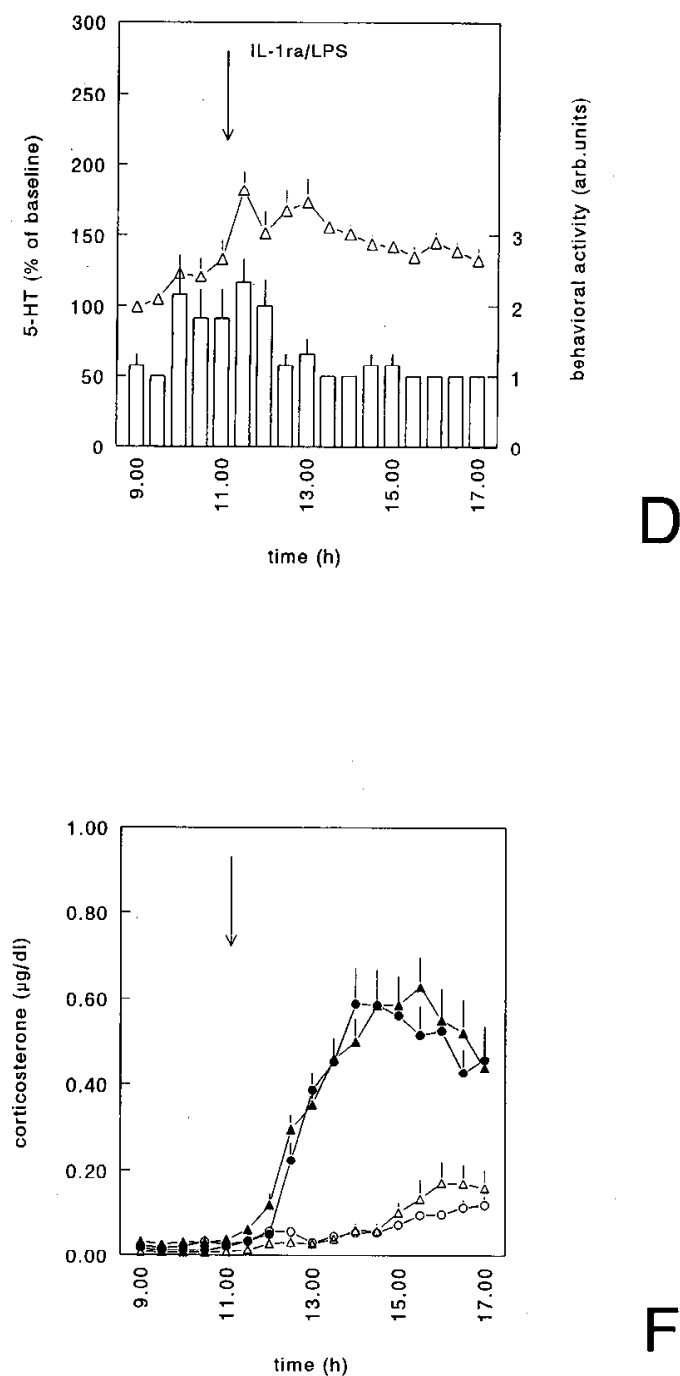

Figure 7. Effects of i.p. administration of LPS $(100 \mu \mathrm{g} / \mathrm{kg}$ body weight; $B)$ and of i.c.v. pretreatment with IL-1 ra $(D)$ on hippocampal extracellular concentrations of 5-HT and on behavioral activity. The results obtained in the respective control groups, i.c.v. saline/i.p. saline- and i.c.v. IL-1ra/ i.p. saline-treated rats, are shown in A and C. Extracellular levels of 5-HT are expressed as percent of baseline (for definition of "baseline," see Calculations and statistical procedures in Materials and Methods) and are depicted as open triangles. The corresponding behavioral activity scores 
into the circulation with different kinetics of appearance (Michie et al., 1988; Shalaby et al., 1989; Zanetti et al., 1992; Pollmächer et al., 1993). In addition, these cytokines are individually able, but with varying efficacy, to stimulate HPA hormone secretion (for review see Besedovsky and Del Rey, 1992; Schöhitz et al., 1994; Tilders et al., 1994). The here-presented data and the above-cited literature may therefore point, in analogy with the HPA axis response to LPS, to multifactorial mechanisms for LPS to affect hippocampal serotonergic neurotransmission. Whether cytokines are being produced in the brain after an i.p.-administered immune stimulant is still subject of extensive research. Recent studies have forwarded evidence for IL-1 production in the hippocampus $2 \mathrm{hr}$ (mouse, Takao et al., 1993) and $6 \mathrm{hr}$ (rat, Quan et al., 1994) after peripheral administration of LPS. Ban et al. (1992) found induction of IL- $1 \alpha$ mRNA and IL-1 $\beta$ mRNA in distinct regions of the brain after i.v. injection of LPS in mice. In our study, centrally acting IL- 1 appears to participate in the effects of peripherally administered LPS on hippocampal serotonergic neurotransmission, although this conclusion is based on indirect evidence. Therefore, the molecular and pharmacological mechanisms (and their time courses) underlying the action of peripherally administered LPS on CNS parameters remain for a large part to be elucidated.

The exact neuroanatomical site at which i.c.v.-administered IL- 1 exerts its action is still unclear. However, since IL-1 ra displays only low affinity for binding the type 2 IL-1 receptor, the antagonistic properties of IL-1ra on the i.c.v. IL- $1 \beta$-induced increases in extracellular 5-HT, 5-HIAA, corticosterone, and decrease in behavioral activity strongly suggest an involvement of the type $1 \mathrm{IL}-1$ receptor as mediator of these effects. IL-1 receptor binding (Takao et al., 1990) and type 1 IL-1 receptor mRNA expression (Cunningham et al., 1992) have been shown particularly in the granular cell layer of the murine dentate gyrus, whereas substantial expression was also present in the raphe nuclei. In contrast to the restricted pattern found in the mouse, IL-1 binding sites, type 1 IL-1 receptor mRNA, and IL-1 mRNA appear to be widely distributed in the rat brain (Farrar et al., 1987a,b; Katsuura et al., 1988; Ericsson et al., 1993). Farrar et al. (1987a) observed high densities of IL-1 binding in the granular cell layer of the dentate gyrus and the pyramidal cell layer of the rat hippocampus, although this was not found by others (Takao et al., 1990; IIaour et al., 1992). Thus, the exact neuroanatomical localization of the type $1 \mathrm{IL}-1$ receptor in the rat is not fully identified and our findings on i.c.v.-administered hIL$1 \beta$ may be mediated by hippocampal, raphe, or hypothalamic receptors, or alternatively by a trans-synaptic mechanism via IL-1 receptors located elsewhere in the brain.

Previous biochemical and electrophysiological studies have shown that glucocorticoids exert profound effects on the raphehippocampal serotonergic system (recently reviewed by Chaouloff, 1993; see also de Kloet, 1991). Hence, it has been reported that corticosterone increases the turnover rate of 5-HT in the hippocampus (Azmitia and McEwen, 1974; Van Loon et al..
1981; de Kloet et al., 1982; Singh et al., 1990). The effects of corticosterone in the brain are mediated by two types of intracellular receptors: mineralocorticoid receptors (MR) and glucocorticoid receptors (GR; Reul and de Kloet, 1985; Reul et al., 1990; recently reviewed by de Kloet, 1991). Both types of receptors are expressed in the rat hippocampus (Reul and de Kloet, 1985; Reul et al., 1989) and are believed to be coexpressed in pyramidal and dentate gyrus neurons (Reul and De Kloet, 1986; Van Eekelen et al., 1988; Herman et al., 1989). Recent electrophysiological studies have shown that corticosterone via MR suppresses the 5-HT-induced hyperpolarization of $\mathrm{CA}_{1}$ pyramidal neurons (Joëls et al., 1991). Conversely, evidence in favor of a direct influence of hippocampal 5-HT on HPA axis regulation is scarce. Recent studies suggest that the raphe-hippocampal serotonergic system is involved in the regulation of hippocampal MR and GR expression (Seckl et al., 1990), which would represent an indirect means of HPA axis regulation by hippocampal 5-HT. However, the time frame of such effects (days) may be beyond the responses observed in the present study (hours). To gain insight into the putative relationship between the raphe-hippocampal serotonergic system and the HPA axis, a careful examination of the time course of IL-1 $\beta$-induced changes in corticosterone and 5-HT appears of interest. After i.c.v. application of IL-1, corticosterone levels increased much more rapidly than hippocampal 5-HT concentrations, and reached maximum about $30-60 \mathrm{~min}$ earlier. This observation argues against the possibility that an increased 5-HT level in the hippocampus is causally related to the elevation in corticosterone levels, but rather points to the possibility that the increased glucocorticoid levels may be implicated in the rise in serotonergic neurotransmission. However, the concentrations of hippocampal 5-HT after i.c.v.-applied IL-1 $\beta$ declined rapidly to baseline values, whereas corticosterone levels remained elevated during the whole experiment. This observation points either to the participation of additional factors besides glucocorticoids in the 5-HT response to hIL-1 $\beta$ or to the possibility that the responses in corticosterone and 5-HT are not interrelated. In contrast to the effect of hIL-1 $\beta$, the time courses of the effect of LPS on corticosterone and 5-HT were highly parallel, which underscores a role of multiple (LPS-induced) factors-each with its own effective time span and amplitude-in the control of raphe-hippocampal serotonergic neurotransmission and HPA axis activity. Our data on the effect of i.c.v. IL-1ra pretreatment before i.p. LPS administration are consistent with this notion.

Until now most research in the field of neuroimmunology was focused on effects of an immune challenge and cytokines at the level of the hypothalamus/preoptic region without much attention to higher brain structures. Although the hippocampus as part of the limbic system is highly involved in the regulation of mechanisms subserving homeostasis of the organism (for review, see De Kloet, 1991), its role in the responses after an immune challenge is not fully understood. The present study shows that the raphe-hippocampal serotonergic system partici-

(expressed as arbitrary units; see Experimental protocols in Materials and Methods) are depicted as bars. Values represent means \pm SEM ( $n=6-$ 7). $E$ and $F$ represent the effects of i.p. administration of LPS and of i.c.v. pretreatment with IL-1ra on hippocampal extracellular concentrations of 5-HIAA (percent of baseline, mean \pm SEM) and dialysate corticosterone ( $\mu \mathrm{g} / \mathrm{dl}$, mean $\pm \mathrm{SEM}$ ), respectively. Regarding these paradigms [5HIAA $(\mathrm{E})$ and corticosterone $(\mathrm{F})]$, the four experimental groups are depicted as follows: i.c.v. saline/i.p. saline-treated rats, open circles $(n=6)$; i.c.v. saline/i.p. LPS-treated rats, closed circles $(n=7)$; i.c.v. IL-1ra/i.p. saline-treated rats, open triangles $(n=6)$; and i.c.v. IL-1 ra/i.p. LPS-treated rats, closed triangles $(n=6)$. Samples were collected every $30 \mathrm{~min}$ as described under protocol $\mathrm{D}$. The time point of the injections is indicated by the arrow (i.p. injection followed 6 min after i.c.v. pretreatment). Time points on the x-axis correspond with the time at which collection of the respective sample was started. 


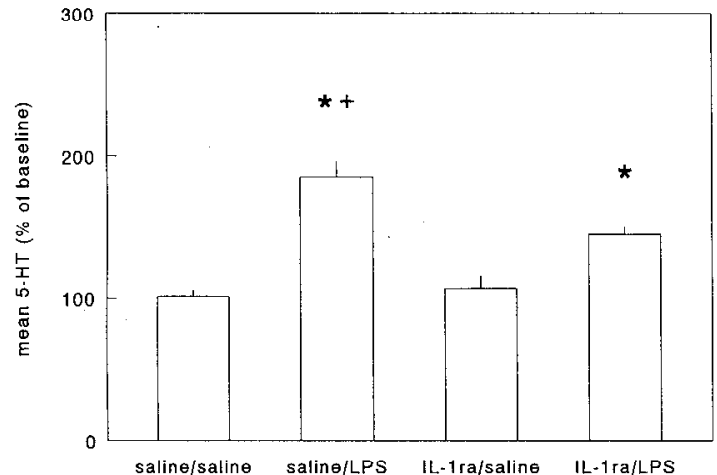

A

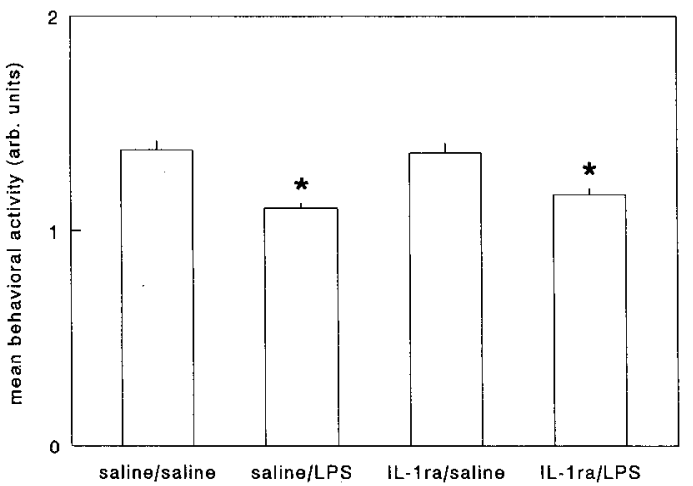

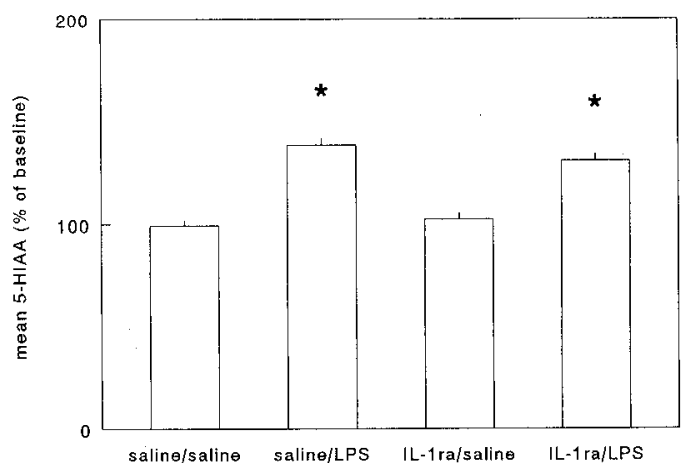

B

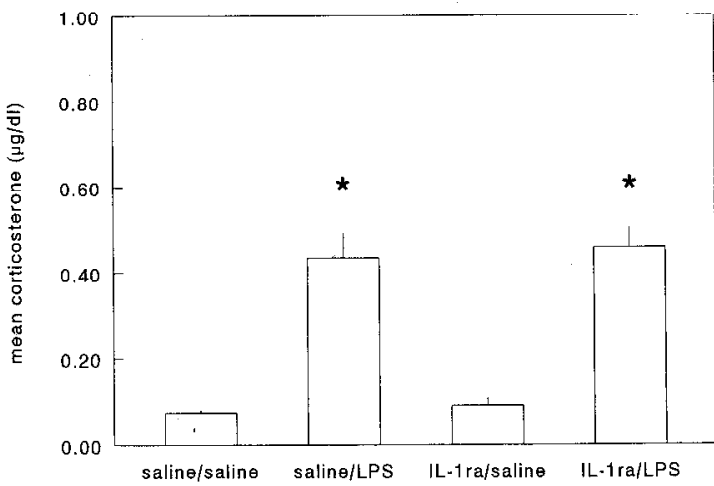

C

Figure 8. Mean values of hippocampal extracellular concentrations of 5-HT $(A), 5$-HIAA $(B)$, and dialysate corticosterone $(D)$, and of behavioral activity scores $(C)$ for the period after i.p. injection of saline or LPS (100 $\mu \mathrm{g} / \mathrm{kg}$ body weight) and i.c.v. pretreatment with saline or IL-1ra as deducted from the time curves presented in Figure 7. There were four experimental groups: i.c.v. saline/i.p. saline-, i.c.v. saline/i.p. LPS-, i.c.v. IL1 ra/i.p. saline-, and i.c.v. IL-1ra/i.p. LPS-treated rats. Samples were collected every $30 \mathrm{~min}$ as described under protocol D. Extracellular levels of 5-HT and 5-HIAA are expressed as percent of baseline (for definition of "baseline," see Calculations and statistical procedures in Materials and Methods). The behavioral activity scores are expressed as arbitrary units (see Experimental protocols in Materials and Methods). Corticosterone concentrations are expressed as $\mu \mathrm{g} / \mathrm{dl}$. ${ }^{*}$, significantly different from its respective control group; + , significantly different from i.c.v. IL-1ra/i.p. LPS-treated rats (Duncan multiple range test).

pates in the CNS responses to an immune stimulus. Moreover, our data suggest that centrally acting IL-1 largely contributes to the hippocampal serotonergic neurotransmission changes observed following a peripheral immune challenge.

\section{References}

Azmitia EC, McEwen BS (1974) Adrenocortical influence on rat tryptophan hydroxylase activity. Brain Res 78:291-203.

Ban E, Haour F, Lenstra R (1992) Brain interleukin 1 gene expression induced by peripheral lipopolysaccharide administration. Cytokine $4: 48-54$.

Bateman A, Singh A, Kral T, Solomon S (1989) The immune-hypothalamic-pituitary-adrenal axis. Endocr Rev 10:92-112.

Berkenbosch F, Van Oers J, Del Rey A, Tilders F, Besedovsky H (1987) Corticotropin-releasing factor-producing neurons in the rat activated by interleukin-1. Science 238:524-526.

Besedovsky HO, Del Rey A (1992) Immune-neuroendocrine circuits: integrative role of cytokines. Front Neuroendocrinol 13:61-94.

Brakkee JH, Wiegant VM, Gispen WH (1979) A simple technique for rapid implantation of a permanent cannula into the rat brain ventricular system. Lab Anim Sci 29:78-91.
Chaouloff F (1993) Physiopharmacological interactions between stress hormones and central serotonergic systems. Brain Res Rev 18:1-32.

Cunningham ET Jr, Wada E, Carter DB, Tracey DE, Battey JF, De Souza EB (1992) In situ histochemical localization of type I interleukin-1 receptor messenger RNA in the central nervous system, pituitary, and adrenal gland of the mouse. J Neurosei 12:1101-1114.

De Kloet ER (1991) Brain corticosteroid receptor balance and homeostatic control. Front Neuroendocrinol 12:95-164.

De Kloet ER, Kovacs GL, Szabo G, Telegdy G, Bohus B, Versteeg DHG (1982) Decreased serotonin turnover shortly after adrenalectomy: selective normalization after corticosterone substitution. Brain Res 239:259-263.

Dunn AJ (1988) Systemic interleukin-I administration stimulates hypothalamic norepinephrine metabolism paralleling the increased plasma corticosterone. Life S̀ci 43:429-435.

Dunn AJ (1990) Interleukin-1 as stimulator of hormone secretion. Prog Neuroendocrinimmunol 3:26-34

Dunn AJ (1992a) Endotoxin-induced activation of cerebral catecholamine and serotonin metabolism: comparison with interleukin-1. J Pharmacol Exp Ther 261:964-969.

Dunn AJ (1992b) The role of interleukin-1 and tumor necrosis factor $\alpha$ in the neurochemical and neuroendocrine responses to endotoxin. Brain Res Bull 29:807-812. 
Dunn AJ, Vickers SL (1994) Neurochemical and neuroendocrine responses to Newcastle disease virus administration in mice. Brain Res 645:103-112.

Ericsson A, Liu C, Kasckow J, Hart RP, Sawchenko PE (1993) Distribution of the type 1 interleukin- 1 receptor mRNA in the central nervous system of the rat. Proceedings of the 23rd Annual Meeting of the Society for Neuroscience, Washington DC, 45.1.

Farrar WL, Kilian PL, Ruff MR, Hill JM, Pert CB (1987a) Visualization and characterization of interleukin 1 receptors in brain. $J$ Immunol 139:459-463.

Farrar WL, Hill JM, Harel-Bellan A, Vinocour M (1987b) The immune logical brain. Immunol Rev 100:361-378.

Felten SY, Felten DL (1991) Innervation of lymphoid tissue. In: Psychoneuroimmunology, 2d ed (Ader R, Felten DL, Cohen N, eds), pp 27-69. San Diego: Academic.

Gardier AM, Kachaner S, Shaghaghi EK, Blot C, Bohuon C, Jacquot C, Pallardy MJ (1994) Effects of a primary immune response to T-cell dependent antigen on serotonin metabolism in frontal cortex: in vivo microdialysis study in freely moving Fischer 344 rat. Brain Res 645:150-156.

Gemma C, Ghezzi P, De Simoni MG (1991) Activation of the hypothalamic serotonergic system by central interleukin-1. Eur J Pharmacol 209:139-140.

Haour F, Ban E, Marquette C, Milon G, Fillion G (1992) Brain interleukin-1 receptors: mapping, characterization and modulation. In: Interleukin 1 in the brain (Rothwell N, Dantzer R, eds), pp 13-26. Oxford: Pergamon.

Hart BL (1988) Biological basis of the behavior of sick animals. Neurosci Biobehav Rev 12:123-137.

Herman JP, Patel PD, Akil H, Watson SJ (1989) Localization and regulation of glucocorticoid and mineralocorticoid receptor messenger RNAs in the hippocampal formation of the rat. Mol Endocrinol 3:1886-1894.

Hermus ARMM, Sweep CGJ (1990) Cytokines and the hypothalamicpituitary-adrenal axis. J Steroid Biochem Mol Biol 37:867-871.

Jacobs BL, Azmitia EC (1992) Structure and function of the brain serotonin system. Physiol Rev 72:165-229.

Joels M, Hesen W, De Kloet ER (1991) Mineralocorticoid hormones suppress serotonin-induced hyperpolarization of rat hippocampal $\mathrm{CA}_{1}$ neurons. J Neurosci 11:2288-2294.

Kabiersch A, Del Rey A, Honegger CG, Besedovsky HO (1988) Interleukin-1 induces changes in norepinephrine metabolism in the rat brain. Brain Behav Immınol 2:267-274.

Kalén P, Rosegren E, Lindvall O, Björklund A (1989) Hippocampal noradrenaline and serotonin release over 24 hours as measured by the dialysis technique in frecly moving rats: correlation to behavioural activity state, effect of handling and tail-pinch. Eur J Neurosci 1:181-188.

Katsuki H, Nakai S, Hirai Y, Akaji K, Kiso Y, Satoh M (1990) Interleukin-1 $\beta$ inhibits long-term potentiation in the CA3 region of mouse hippocampal slices. Eur J Pharmacol 181:323-326.

Katsuura G, Gottschall PE, Arimura A (1988) Identification of a highaffinity receptor for interleukin-1 beta in rat brain. Biochem Biophys Res Commun 156:61-67.

Kent S, Bluthé R-M, Kelley KW, Dantzer R (1992) Sickness behavior as a new target for drug development. Trends Pharmacol Sci 13:2428.

Kushner I (1982) The phenomenon of the acute phase response. Ann NY Acad Sci 389:39-48.

Linthorst ACE, Flachskanm C, Holsbuer F, Reul JMHM (1994) Local administration of recombinant human interleukin- $1 \beta$ in the rat hippocampus increases serotonergic neurotransmission, hypothalamicpituitary-adrenocortical axis activity, and body temperature. Endocrinology 135:520-532.

Mefford IN, Heyes MP (1990) Increased biogenic amine release in mouse hypothalamus following immunological challenge: antagonism by indomethacin. J Neuroimmunol 27:55-61.

Michie HR, Manogue KR, Spriggs DR, Revhaug A, O'Dwyer S, Dinarello CA, Cerami A, Wolff SM, Wilmore DW (1988) Detection of circulating tumor necrosis factor after endotoxin administration. $\mathrm{N}$ Engl J Med 318:1481-1486.

Miller LG, Galpern WR, Dunlap K, Dinarello CA, Turner TJ (1991) Interleukin- 1 augments gamma-aminobutyric acid $_{\mathrm{a}}$ receptor function in brain. Mol Pharmacol 39:105-108.

Mohankumar PS, Quadri SK (1993) Systemic administration of inter- leukin-1 stimulates norepinephrine release in the paraventricular nucleus. Life Sci 52:1961-1967.

Mohankumar PS, Thyagarajan S, Quadri SK (1991) Interleukin-1 stimulates the release of dopamine and dihydroxyphenylacetic acid from the hypothalamus in vivo. Life Sci 48:925-930.

Mohankumar PS, Thyagarajan S, Quadri SK (1993) Interleukin-1 beta increases 5-hydroxyindoleacetic acid release in the hypothalamus in vivo. Brain Res Bull 31:745-748.

Navarra P, Tsagarakis S, Faria MS, Rees LH, Besser GM, Grossman AB (1991) Interleukins-1 and - 6 stimulate the release of corticotropin-releasing hormone-41 from rat hypothalamus in vitro via the eicosanoid cyclooxygenase pathway. Endocrinology 128:37-44.

Upp MK, Obàl F Jr, Krueger JM (1991) Interleukin 1 alters rat sleep: temporal and dose-related effects. Am J Physiol 260:R52-R58.

Ovadia H, Abramsky O, Barak V, Conforti N, Saphier D, Weidenfeld J (1989) Effect of interleukin-1 on adrenocortical activity in intact and hypothalamic deafferentated male rats. Exp Brain Res 76:246-249.

Palazzolo DL, Quadri SK (1992) Interleukin-1 inhibits serotonin release from the hypothalamus in vitro. Life Sci 51:1797-1802.

Paxinos G, Watson C (1982) The rat brain in stereotactic coordinates. Sydncy: Academic.

Payne LC, Obal F Jr, Opp MR, Krueger JM (1992) Stimulation and inhibition of growth hormone secretion by interleukin-1 $\beta$ : the involvement of growth hormone-releasing hormone. Neuroendocrinology $56: 118-123$

Plata-Salamán CR, FFrench-Mullen JMH (1992) Interleukin-1 $\beta$ depresses calcium currents in CA1 hippocampal neurons at pathophysiological concentrations. Brain Res Bull 29:221-223.

Pollmächer T, Schreiber W, Gudewill S, Vedder H, Fassbender K, Wiedemann K, Trachsel L, Galanos C, Holsboer F (1993) Influence of endotoxin on nocturnal sleep in humans. Am J Physiol 264:R1077R1083.

Quan N, Sundar SK, Weiss JM (1994) Induction of interleukin-1 in various brain regions after peripheral and central injections of lipopolysaccladride. J Neuroimmunol 49:125-134.

Rada P, Mark GP, Vitek MP, Mangano RM, Blume AJ, Beer B, Hoebel BG (1991) Interleukin-1 $\beta$ decreases acetylcholine measured by microdialysis in the hippocampus of freely moving rats. Brain Res 550: $287-290$.

Rettori V, Jurcovicova J, McCann SM (1987) Central action of interleukin-1 in altering the release of TSH, growth hormone, and prolactin in the male rat. J Neurosci Res 18:179-183.

Reul JMHM, De Kloet ER (1985) Two receptor systems for corticosterone in rat brain: microdistribution and differential occupation. Endocrinology 117:2505-2511.

Reul JMIM, De Kloet ER (1986) Anatomical resolution of two types of corticosterone receptor sites in rat brain with in vivo autoradiography and computerized image analysis. J Steroid Biochem 24:269 272.

Reul JMHM, Pearce PT, Funder JW, Krozowski ZS (1989) Type I and type II corticosteroid receptor gene expression in the rat: effect of adrenalectomy and dexamethasone administration. Mol Endocrinol 3:1674-1680.

Reul JMHM, De Kloet ER, Van Sluijs FJ, Rijnberk A, Rothuizen J (1990) Binding characteristics of mineralocorticoid and glucocorticoid receptors in dog brain and pituitary. Endocrinology 127:907915.

Rothwell NJ (1991) Functions and mechanisms of interleukin 1 in the brain. Trends Pharmacol Sci 12:430-436.

Sapolsky R, Rivier C, Yamamoto G, Plotsky P, Vale W (1987) Interleukin-1 stimulates the secretion of hypothalamic corticotropin-releasing factor. Science 238:522-524.

Sawada M, Hara N, Maeno T (1992) Reduction of the acetylcholineinduced $\mathrm{K}^{+}$current in identified Aplysia neurons by human interleukin-1 and interleukin-2. Cell Mol Neurobiol 12:439-445.

Schöbitz B, De Kloet ER, Holsboer F (1994) Gene expression and function of interleukin 1 , interleukin 6 and tumor necrosis factor in the brain. Prog Neurobiol 44:397-432.

Seckl JR, Dickson KL, Fink G (1990) Central 5,7-dihydroxytryptamine lesions decrease hippocampal glucocorticoid and mineralocorticoid receptor messenger ribonucleic acid expression. J Neuroendocrinol 2:911-916.

Shalaby MR, Waage A, Aarden L, Espevik T (1989) Endotoxin, tumor necrosis factor- $\alpha$ and interleukin 1 induce interleukin 6 production in vivo. Clin Immunol Immunopathol 53:488-. 
Shintani F, Kanba S, Nakaki T, Nibuya M, Kinoshita N, Suzuki E, Yagi G, Kato R, Asai M (1993) Interleukin-1 $\beta$ augments release of norepinephrine, dopamine, and serotonin in the rat anterior hypothalamus. J Neurosci 13:3574-3581.

Singh VB, Corley KC, Phan TH, Boadle-Biber MC (1990) Increases in the activity of tryptophan hydroxylase and midbrain in response to acute or repeated sound stress are blocked by adrenalectomy and restored by dexamethasone treatment. Brain Res 516:66-76.

Swanson LW, Köhler C, Björklund A (1987) The limbic region. I: The septohippocampal system. In: Handbook of chemical neuroanatomy, Vol 5, Integrated systems of the CNS, Pt I (Björklund A, Hökfelt T, Swanson LW, eds), pp 125-277. Amsterdam: Elsevier.

Takao T, Tracey DE, Mitchell WM, De Souza EB (1990) Interleukin-1 receptors in mouse brain: characterization and neuronal localization. Endocrinology 127:3070-3078.

Takao T, Culp SG, De Souza EB (1993) Reciprocal modulation of interleukin-1-beta (IL-1-beta) and IL-1 receptors by lipopolysaccharide (endotoxin) treatment in the mouse brain endocrine immune axis. Endocrinology 132:1497-1504.

Tilders FJH, DeRijk RH, Van Dam A-M, Vincent VAM, Schotanus K, Persoons JHA (1994) Activation of the hypothalamus-pituitary-adrenal axis by bacterial endotoxins: routes and intermediate signals. Psychoneuroendocrinology 19:209-232.

Trulson ME, Jacobs BL (1979) Raphe unit activity in freely moving cats: correlation with level of behavioral arousal. Brain Res 163:135150.

Tsagarakis S, Gillies G, Rees LH, Besser M, Grossman A (1989) In- terleukin- 1 directly stimulates the release of corticotrophin releasing factor from rat hypothalamus. Neuroendocrinology 49:98-101.

Uehara A, Gottschall PE, Dahl RR, Arimura A (1987) Interleukin-1 stimulates ACTH release by an indirect action which requires endogenous corticotropin releasing factor. Endocrinology 121:1580-1582.

Van Eekelen JAM, Jiang W, De Kloet ER, Bohn MC (1988) Distribution of the mineralocorticoid and the glucocorticoid receptor mRNAs in the rat hippocampus. J Neurosci Res 21:88-94.

Van Loon GR, Shum A, Sole MJ (1981) Decreased brain serotonin turnover after short term (two hour) adrenalectomy in rats: a comparison of four turnover methods. Endocrinology 108:1392-1402.

Wilkinson LO, Auerbach SB, Jacobs BL (1991) Extracellular serotonin levels change with behavioral state but not with pyrogen-induced hyperthermia. J Neurosci 11:2732-2741.

Woodroofe MN, Sarna GS, Wadhwa M, Hayes GM, Loughlin AJ, Tinker A, Cuzner ML (1991) Detection of interleukin-1 and interleukin-6 in adult rat brain, following mechanical injury, by in vivo microdialysis: evidence of a role for microglia in cytokine production. J Neuroimmunol 33:227-236.

Zalcman S, Green-Johnson JM, Murray L, Nance DM, Dyck D, Anisman H, Greenberg AH (1994) Cytokine-specific central monoamine alterations induced by interleukin- $1,-2$ and -6 . Brain Res 643:40-49.

Zanetti G, Heumann D, Gerain J, Kohler J, Abbet P, Barras C, Lucas R, Glauser M-P, Baumgartner J-D (1992) Cytokine production after intravenous or peritoneal gram negative bacterial challenge in mice. J Immunol 148:1890-1897.

Zeise ML, Madamba S, Siggins GR (1992) Interleukin-1 $\beta$ increases synaptic inhibition in rat hippocampal pyramidal neurons in vitro. Regul Pept 39:1-7. 